\title{
A Theory of Currency Board with Irrevocable Commitments ${ }^{*}$
}

by

\author{
Alex Chan \\ The University of Hong Kong \\ and \\ Nai-fu Chen \\ University of California, Irvine
}

JEL classification: $\mathrm{F} 310, \mathrm{E} 520$

Keywords: Currency board, Hong Kong, Argentina, irrevocable reserve commitment, put option, exchange rate insurance

Many of the ideas in this paper were jointly developed with Merton Miller in 1998 during the Asian Currency Crisis. We benefited greatly from his insight, though the first complete draft was finished after he passed away in June 2000 . We are also grateful to Jeremy Berkowitz, Sudipto Dasgupta, Juha Tarkka, Chi-wa Yuen, participants of HKEA 2000 conference in Hong Kong, FEMES 2001 conference in Osaka, and workshop participants in the Hong Kong University of Science and Technology and the Swedish School of Economics (Helsinki) for their helpful comments, and the financial support from Hong Kong RGC earmarked research grant HKU7137/00H.

Chan is from the School of Economics and Finance, The University of Hong Kong, K.K.Leung Building, Pokfulam Road, Hong Kong (Tel: (852)-2857-8510, Fax: (852)-2548-1152, and Email: alexchan@econ.hku.hk).

Corresponding author: Chen is from the Graduate School of Management, University of California, Irvine, CA92697, U.S.A. Email: nchen@uci.edu. 


\title{
A Theory of Currency Board with Irrevocable Commitments
}

\begin{abstract}
Currency boards are subject to runs if the foreign currency reserve is insufficient to back the convertible money supply. We construct a simple model capturing the main features of a currency board to analyze a government's decision to maintain or abandon a currency board based on the costs and benefits. Furthermore, we show how pre-specified commitments can enhance the credibility of a currency board and avert runs, and determine what the optimal reserve commitment should be. If there exists asymmetric information on the government's resolve, the government can use commitments as a costly signal to induce a separating equilibrium. The model can be adapted to analyze other hard-fixed exchange rate systems such as dollarizations and monetary unions. We illustrate the implications of our model in terms of the recent success in Hong Kong and remedies for Argentina.
\end{abstract}




\section{Introduction}

Recent financial crises beleaguering Argentina in 2001-02 and East Asia in 1997-98 have brought to focus issues related to the stability of fixed exchange rate policies. At the same time, however, the world's currency markets are gravitating towards an arrangement dominated by a few pivotal currencies upon which the other currencies can anchor with a formal or informal fixed exchange rate. This is a theme receiving significant attention in the recent academic literature [see, e.g., Miller (1998a, 1998b, 2000) and Mundell (2000)] and international economic forums $\square$

A currency board is a specific fixed exchange rate arrangement whereby the monetary authority issues domestic currency convertible into a linked reserve currency on demand. It passively stands ready to exchange the linked reserve currency with the domestic currency at the official "hard-fixed" exchange rate in response to the requests of (foreign and domestic) currency holders. A currency board arrangement was adopted by Hong Kong to stabilize its currency in 1983 and by Argentina in 1991 to tame its runaway hyperinflation (about 5,000 percent in 1989 and 1,300 percent in 1990). It has also been adopted by emerging economies like Estonia, Lithuania and Bulgaria, and under considerations by others [see Hanke (2002)]. The recent dollarization programs adopted by Panama, El Salvador and Ecuador are equivalent to (except for seigniorage) a perfectly run currency board. Furthermore, a monetary union can also be viewed as a variation of the same general concept of a "hard-fixed" exchange rate system. $\square$

Almost all currency boards are successful, with one exception. Despite its initial success of bringing to Argentina one of the world's highest real growth rates in the period 1991-97 and fending off currency speculations against Argentina in 1995 during the Mexican peso crisis, the Argentine currency board collapsed in 2001-02. This is in stark contrast with the Hong Kong currency board which has always been successful in defending its currency, especially during the

\footnotetext{
${ }^{1}$ See, e.g., IMF Economic Forum “One World, One Currency: Destination or Delusion?” November 2000, discussion by Maurice Obstfeld, Paul Masson and Robert Mundell. (www.imf.org/external/np/tr/2000/TR001108.htm).

${ }^{2}$ Many of the same issues pertaining to "hard-fixed" exchange rate systems, such as a currency board system, a dollarization program or a monetary union, are discussed in the seminal paper by Mundell (1961) on optimal currency areas. See also a book on monetary integration by De Grauwe (1997). We would like to thank Juha Tarkka, chief economist at the Bank of Finland, for in-depth discussions of the similarities and the differences among the various systems. Documentations on the technical details of the European monetary union are available at the European Central Bank website (www.ecb.int). For a thorough discussion on currency boards, see Hanke, Jonung and Schuler (1993).
} 
1997-98 East Asian and Russian financial crises. This paper presents a theoretical model for analyzing the stability of this monetary system. Within this theoretical framework, we analyze a foreign reserve commitment policy proposed by Miller (1998a) and Chan and Chen (1999) [thereafter CCM] for enhancing the stability of a currency board.

The stability of fixed exchange rate systems has been the subject of investigation using different exchange rate crisis models. The first group of crisis models follows the idea from the seminal work of Krugman (1979). It assumes that a government is taking a passive role using foreign currency reserves to defend speculations on the fixed exchange rate system. But due to inconsistencies in the fundamentals for monetary, fiscal and exchange rate policies, the reserve level drops. When the reserve level drops to a critical minimum level, the fixed exchange rate system collapses and the currency is forced to devalue. In reality, however, governments adopting a fixed exchange rate usually take an active role in defending their exchange rate systems through direct interventions. More importantly, in many cases of abandoning fixed exchange rate systems, the reserve levels did not drop to some critical minimum levels. These unexplained empirical evidences lead to the development of the next group of exchange rate crisis models.

The second group of models is labeled as the "New Crisis Model" by Krugman (1996) and others. These models assume that apart from defending the fixed exchange rate system, governments have other objectives such as unemployment rates and production outputs of the economy. In defending the exchange rate, the government has to solve an optimization problem between the costs and benefits of defending the exchange rate. Obstfeld (1996) considers a government which has the (publicly known) dual objectives of maintaining the exchange rate system and maintaining a high production level, and illustrates the instability of the fixed exchange rate system within the context of multiple rational equilibriums. Bensaid and Jeanne (1997) look at the case of a government which maintains a fixed exchange rate system but worries about the cost on its economy when it has to defend the exchange rate with a high interest rate. As speculators understand that the high interest rate cost makes the government more inclined to devalue, it in turn reinforces the speculation. This process may eventually generate self-fulfilling currency crises. Both Obstfeld (1996) and Bensaid and Jeanne (1997) find that, given the incentives of the government to devalue, the belief of the speculators generates a 
self-fulfilling currency crisis in a fixed exchange rate system (e.g., the collapse of the European "Exchange Rate Mechanism," ERM, in 1993).

The existing literature for currency crisis models is mostly limited to actively managed fixed exchange rate systems. Few of them investigate a passive "hard-fixed" exchange rate arrangement such as a currency board. Apart from a similar objective of maintaining a stable exchange rate, there are two major differences between a currency board arrangement and an actively managed exchange rate system. First, governments with an actively managed fixed exchange rate system may directly intervene in foreign exchange market, drain liquidity from the domestic money market and lift interest rates in order to raise the cost to speculators, while a currency board arrangement is a passive monetary system without discretion. The lack of discretion is what gives a currency board its credibility. This is reflected in the predominantly successful history of currency boards, with Argentina as the lone exception. In contrast, an actively managed fixed exchange rate system fails very often (e.g., in recent history, the ERM, Mexico, East Asian countries, Russia, Brazil, Turkey and others). Second, a government adopting a currency board arrangement gives up its monetary policy and it is taking a passive role in the creation process of money supply. Any change in the domestic money supply corresponds to a change in foreign reserve holding of the currency board. On the other hand, governments adopting an actively managed fixed exchange rate system often retain some discretion over their monetary policies. Thus, the dynamics are quite different between the two systems.

This paper develops a formal theoretical model for analyzing the stability of a currency board arrangement for a government with a limited amount of foreign reserve, which is not enough to fully back the domestic money supply (including notes and coins and bank deposits that are readily convertible in the foreign exchange market) at the pre-specified linked exchange rate. As such, the stability of the currency board depends critically on the public confidence. The public, however, does not usually have perfect information on the resolve of the government in maintaining the currency board. CCM argue that a government with strong resolve to defend its currency board can enhance the public confidence through the issuance of a limited amount of currency put option or exchange rate insurance policy The key point of their proposal is to

\footnotetext{
${ }^{3}$ The Chan-Chen put option scheme was formulated in a proposal to the Financial Secretary of Hong Kong in November 1997 and analyzed in Chan and Chen (1999). A related scheme was proposed by Merton Miller to the Premier of China in 1998. See also Miller (1998a) and Culp, Hanke and Miller (1999). These schemes were reported in international media, such as
} 
reveal the resolve (which is unobservable) of the government to the public with an explicit irrevocable reserve commitment (a costly signal). The public can then infer the resolve of their government from the commitment, which would then induce a separating equilibrium. We examine the potential benefits of this commitment policy in enhancing the stability of a currency board and determine what the optimal reserve commitment level should be.

As a historical note, although our model was motivated by the East Asian financial crises in 1997-98, the recent collapse of the Argentina currency board served as an out-of-sample example. The Argentine and the Hong Kong economies were very different during their crises. Argentina was plagued with an inflexible labor market, unsustainable fiscal policies and a prolonged divergence between the US and Argentine economies (often cited as a major danger to sustaining a monetary union) while Hong Kong has always had a flexible labor market and a huge government surplus. In November 2001, the people of Argentina started a run on its banking system after losing confidence in its currency. The government imposed a partial bank freeze on December 1 and later an extended banking holiday that halted most banking and exchange transactions that cumulated in the collapse of its currency board. This is in stark contrast to the Hong Kong experience. After the Russian default in 1998, the Hong Kong Monetary Authority adopted an equivalent version of the CCM proposal in September 1998 to stop the exodus of capital from Hong Kong [see Chen (2001)]. In the end, the Hong Kong dollar was one of the few freely traded hard currencies that did not depreciate against the US dollar during the East Asian and Russian financial crisis years of 1997-98.

The outline of this paper is as follows. Section describes a simple model of a currency board with limited foreign reserves (insufficient to back the convertible money supply at the official linked exchange rate). Section 3 fnodels a reserve commitment for enhancing the stability

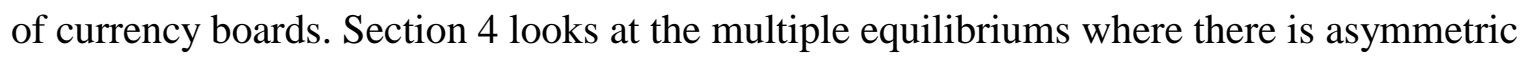
information between the government and the currency holders, and examines the signaling role of commitments. We calibrate our model using Hong Kong and Argentina as examples and discuss the implications and remedies suggested by the model. Section 5 goncludes the paper.

The Economist, Business Week, Financial Times, Fortune, Risk, Wall Street Journal, CNN and others during the Asian Financial Crisis in 1998. 


\section{The Model}

We consider a small open economy adopting a currency board arrangement to link its currency with a major foreign currency. Without loss of generality, we assume that the official linked exchange rate of the domestic currency in terms of the foreign currency, $\bar{e}$, is one.

$$
\bar{e}=1
$$

\subsection{The Autopilot of a Currency Board and its Reserve-backing Requirement}

A currency board stands ready to exchange the linked foreign reserve currency with the domestic currency at an official pre-specified exchange rate. Under this arrangement, not only the exchange rate and the interest rate of the domestic currency are linked to those of the reserve currency, but the creation of domestic currency is also linked to the flow of the reserve currency. An increase in the demand for domestic currency will create an upward pressure on the domestic interest rate and an appreciation pressure on the exchange rate. This will induce an inflow of the reserve currency to the currency board and create an expansion of the domestic money supply. Hence, both the domestic money supply and the foreign reserve holding rise and the market exchange rate will stabilize at the linked exchange rate level. On the other hand, a decrease in demand for domestic currency works in exactly the opposite way and it will induce an outflow of the reserve currency from the currency board and a contraction of domestic currency supply. Consequently, both of the domestic money supply and foreign reserve holding drop and the market exchange rate will again stabilize at the linked exchange rate level. This equilibrating process is commonly known as the "autopilot" of a currency board. For the autopilot to function properly, it is critical that the public believes that the currency board will persist at its current linked exchange rate.

When the currency board is on autopilot, any change in money supply will lead to a corresponding change in the foreign reserve holding of government. Hence,

$$
\bar{e} \times \Delta M=\Delta R
$$

where $\Delta M$ is the change in money supply of domestic currency and $\Delta R$ is the change in foreign

reserve holding of government. Furthermore, since we assume that $\bar{e}=1$, we have

$$
\Delta M=\Delta R
$$

This is the reserve-backing requirement of a currency board. 


\subsection{Government's Ability and Determination}

A government's ability and determination are the two major determinants for the persistence of a currency board arrangement. The ability is reflected in the level of foreign reserve holding. Although a government adopting a currency board arrangement has to follow the reserve-backing requirement for any new money creation, it does not mean that a government would have enough foreign reserve to back the existing domestic money supply at the prespecified exchange rate. In reality, the foreign reserve holding of a government is generally not sufficient to back the convertible domestic money supply. Hence, we assume that

$$
R<M
$$

where $R$ is total foreign reserve level and $M$ is the domestic money supply whose convertibility to the reserve currency is guaranteed by the currency board. Due to this inequality, if the demand for domestic currency decreases significantly, the currency board may not have enough foreign currency reserve to support the redemption of the domestic currency at the official linked exchange rate. In this case, the government is forced to abandon the currency board system due to lacking in its ability.

Apart from the level of reserve currency holding, a government's determination is another determinant for the persistence of a currency board system. Usually, a currency board comes under pressure when the domestic price level is too high (for example, in response to a currency devaluation of a competing economy). Since downward movements in the wage and price structures tend to be sticky, maintaining the linked exchange rate often means slower economic growth and higher unemployment rate until the domestic price structure adjusts appropriately. A government's determination is reflected in the level of political pain it is willing to endure for maintaining the currency board. A government with strong ability (sufficient foreign reserve to support the demand for the redemption of the domestic currency) may voluntarily abandon the currency board if its determination to maintain the currency board is weak. It is a policy decision of the government to maintain or abandon the currency board after considering the costs and

\footnotetext{
${ }^{4}$ This condition abstracts away from the possibility that the country would be bailed out by multilateral organizations like IMF. An equivalent condition for a country adopting dollarization would be for the capital outflow to exceed the reserves. A similar crisis would arise for a country in a monetary union experiencing "asymmetric shocks" (relative to other members of the monetary union) when its financial systems get into troubles (similar to those of Argentina in 2001) because the country loses control over its monetary policy and faces restrictions in its fiscal policy in a monetary union, especially if something
} 
benefits. A high determination to maintain the currency board is in a sense equivalent to a high abandonment cost. Hence, government's determination is a key factor for the decision of voluntary abandonment.

To model the abandonment decision, we need to take into account of how the currency board arrangement and the level of reserve benefit the economy. There are at least two important motivations for maintaining a currency board: (i) to eliminate unnecessary volatility of the external value of the domestic currency (as volatility induces risk premiums) and (ii) to inherit the credibility and stability of the reserve currency's inflation policy since a runaway inflation is often considered to be harmful to the economy. It must be the case that the value of the aggregate "domestic economic fundamental" is higher when the currency board is maintained. We model this by assuming that the domestic fundamental is $f_{L}$ when the domestic currency is linked by the currency board and $f_{D}$ when it is delinked and the currency board is abandoned.

Furthermore, we assume that the full value of the economy is affected by the foreign currency reserve level, $R$, of the country. There are numerous reasons why the government of an open economy wants to maintain a foreign currency reserve. A large enough foreign currency reserve, with or without a currency board, can absorb unnecessary volatility in the exchange value of the domestic currency due to temporary liquidity shocks and disruptions in the foreign exchange market, thereby reducing capital flow risks for domestic and international investors 5 .

Thus, we assume that the full value of the economy, $F$, is an increasing function of the reserve, $R$, and it can be expressed as

$$
F= \begin{cases}F_{L}=f_{L}+g \times R & \text { if the currency board is maintained } \\ F_{D}=f_{D}+g \times R & \text { if the currency board is abandoned }\end{cases}
$$

like the "no-bail-out" clause in the Maastricht Treaty is meant to be serious. In December 2001, Argentina went into a fullfledged financial crisis after IMF refused to bail them out for missing the fiscal target imposed by IMF.

${ }^{5}$ We thank Juha Tarkka and his colleagues for sharing their extensive study at the Bank of Finland on foreign currency reserve policies of small and medium size open economies. Cross-sectionally, the most important variable explaining the size of a country's the foreign currency reserve is its international trade (import+export). Based on the recent experience in the East Asian financial crises, the perceived international value of the economy was indeed related to the size of a country's foreign currency reserve. Using the US dollar to measure the ratio of the international value of an economy before and after the crisis, those countries with large reserves have a much higher ratio than those without (after taking into account of the foreign currency reserve itself whose world price is not much affected). 
where $0 \leq f_{D} \leq f_{L}$ and $0<g$ is a constant, $\square_{\text {and }} R$ is the level of foreign currency reserve. The impact of the foreign currency reserve on the value of the economy is reflected in $g \times R$.

All economic fundamental values are assumed to be denominated in the reserve currency

and, without loss of generality, the interest rate for the reserve currency is assumed to be zero, so there is no time value effect on the fundamental values.

\subsection{Change in Money Demand}

We assume the change in the money demand of the domestic currency is composed of two parts. The first one is a change in the demand of the domestic currency because of an exogenous random shock. The second is a panic selling of the domestic currency from the public because of the possibility of a devaluation in the future.

\subsubsection{Public's Change in the Demand of Domestic Currency Due to Potential Devaluation}

The public understands that the domestic currency may fluctuate in value relative to the reserve currency if the currency board is abandoned. If the probability of devaluation is sufficiently small, the convenience yield of holding the domestic currency (for the purpose of conducting all domestic transactions, given that foreign exchange transactions are not costless) together with possibly a small domestic interest rate premium $\square$ exceed the small expected loss from devaluation. There will not be any panic and the money supply will not be much affected. If the threat of devaluation is substantial, the public would be tempted to convert their domestic currency holdings to the reserve currency to protect their value. As the probability of devaluation reaches some critical level, there will be enough of a critical mass of domestic currency holders

\footnotetext{
${ }^{6}$ It may be more realistic to assume that $g$ itself is a function of $R$, where $g(R)$ is positive but decreasing in $R$. Here, we assume a constant $g$ for simplicity and tractability, as the exact functional form is not critical to the main intuition of our model.

${ }^{7}$ In the Hong Kong experience, however, this premium is typically very small (a few basis points) and it fluctuates around zero between positive and negative regions in normal times. During the Asian currency crisis of 1997-98, the premium remained small but positive for most of that period (see Morgan Stanley (1998)), with the exception of the times when the Hong Kong Monetary Authority (HKMA) intentionally drained liquidity and squeezed interest rates to "punish" the speculators [see Chen (2001)]. After the HKMA reformed its currency board in September 1998 to conform more to that of a classical currency board, the interest rate differential between the domestic and reserve currency rates returned to just a few basis points around zero. This was in contrast with the Argentine experience in 2001 when the domestic interest rates were significantly above the US rates because of the significant probability of default (similar to those of US junk bonds), whereas the Hong Kong government bonds have almost zero probability of default because of the huge cumulative government surplus.
} 
wanting to convert to set off a run against the currency board (analogous to a bank run) as in the sequence of events leading to the collapse of the Argentine currency board in $2001 \frac{8}{8}$

To keep the model simple, we assume that there are two outcomes: a good outcome where there is no panic selling and a bad outcome with panic selling (currency board runs) that causes the currency board to fail The two outcomes are separated by a critical probability of devaluation, $p^{*}$, which can be interpreted as the public's tolerance level of the exchange rate risk ${ }^{10}$ The probability of delink, $p$, takes into account of the strategic policy decision of the government. Thus, in our model, we assume that the panic selling quantity $Q$ is given as

$$
Q(p)=\left\{\begin{array}{cl}
Q^{*} & \text { if } p>p^{*} \\
0 & \text { otherwise }
\end{array}\right.
$$

where $Q^{*}>R$.

\subsubsection{Exogenous Demand Contraction Shock for Domestic Currency}

The possibility of delink can also arise from a potential exogenous domestic currency demand contraction shock, $S$, next period at $t=1$. The distribution of the demand contraction shock is assumed to be public information at the present time at $t=0$. At $t=0$, given the distribution of $S$, the government may want to signal its commitment to the currency board; ${ }^{11}$ and then, the domestic currency holders assess the probability of delink and decide whether to run the

${ }^{8}$ On December 1, 2001 (Saturday), faced with an exodus of capital from its own citizens, Argentina placed restrictions on bank deposit withdrawal and convertibility to stop the run against the banks and its currency board. "The draconian measures came after Argentines lined up at the banks on Friday (November 30, 2001) to withdraw their savings." (Financial Times, December 3, 2001) The official abandonment of the Argentine currency board came in January 2002.

${ }^{9}$ In this aspect, many of the issues resemble those of bank runs. See, e.g., Diamond and Dybvig (1983). The main reason of modeling the collapse of a currency board as bank runs is that it corresponds to most cases of fixed exchange rate collapses in the recent currency crises. The most direct causes for the collapse were that local people and businesses lost confidence in the government's resolves to maintain the fixed exchange rate and they started to exchange in the spot market and hedge in the forward market. [See, for example, Miller (1998), IMF reports on the East Asian Crisis and the reports on the collapse of the Argentine currency board.]

${ }^{10}$ It is possible to endogenize $p^{*}$. At a low enough probability of delink, domestic currency holders would gladly hold the domestic currency for its convenience yield (and possibly higher interest rates, see footnote 7). As the probability of delink increases beyond some critical point, there are enough domestic currency holders who want to convert their life savings into the reserve currency to preserve their values and set off a run against the currency board. As in a bank run, once it is started, it will snowball as it is in the interest of everyone to convert. In this paper, we take this stylized fact as an assumption without explicitly modeling it to streamline our analysis.

${ }^{11}$ The commitment policy is mathematically equivalent to a put option. From the put-call parity as applied to currency options, the put option is equivalent to a call and a forward. The availability of the put option does not give speculators new instruments for speculation [see Chan and Chen (1999)]. An implication of the result of this paper is that if the monetary authority acts optimally on the commitment policy, the commitment policy itself will not induce speculation. 
currency board. We assume that this exogenous demand contraction shock has a simple uniform distribution at $t=1$ (conditional on no panic selling at $t=0$ ) as follows:

$$
P\{[S \geq s]\}=\left[\frac{(\alpha+\beta) \times M-s}{2 \beta M}\right], \quad \text { for all } s \in[(\alpha \times M-\beta \times M),(\alpha \times M+\beta \times M)]
$$

where $\alpha$ is a measure of the mean and $\beta$ is a measure of the uncertainty of the exogenous demand contraction shock for domestic currency relative to the money supply, $M$. Thus, for $\alpha=0$, the expected shock has a mean of 0 and a range from $(-\beta \times M)$ to $(+\beta \times M)$. For $\alpha>0$, the mean of the expected contraction is $(\alpha \times M)$. To restrict the size of the shock to be less than the total money supply, we have $-1<\alpha<1,0<\beta \leq 1$, and $|\alpha|+|\beta| \leq 1$. For ease of exposition, we impose the additional restrictions on $\alpha$ and $\beta$ such that [i] $R \leq(\alpha+\beta) \times M$ (i.e., the maximum shock is larger than the reserve to ensure that there is the possibility of involuntary delink) and [ii] $0 \leq(\beta-\alpha)$ (i.e., the minimum shock can be zero or a capital inflow), to streamline the analysis. 2

\section{Figure 1 about here}

After knowing the realized money demand contraction shock, $S$, the government will determine whether to maintain or (strategically / involuntarily) abandon the currency board at time $(t=1)$. The time line for this model is shown in Figure 2.

\section{Figure 2 about here}

If the money demand contraction shock is negative, $(S<0)$, there will be an appreciation pressure on the domestic currency. To simplify the story, we assume that the government will maintain the currency board under an inflow of foreign reserve ${ }^{1}$. On the other hand, if the shock is a decrease in demand for the domestic currency, the government may maintain or abandon the currency board in accordance with its objective function and the size of the shock.

\footnotetext{
12 These two assumptions are not critical to the main points of the paper, but they significantly simplify the analysis as we do not need to break up the proofs into many sub-cases that do not add to the intuition of the model.

${ }^{13}$ The flow of foreign reserve is assumed to be publicly observable (e.g., from the website of central banks).
} 


\subsection{Decision of Government:}

If the government perceives that it cannot prevent public's panic selling at $t=0$ (even with the possibility of signaling its resolves), the government will abandon the currency board immediately to preserve the foreign reserves currency. If the realization of the demand shock at $t=1$ is larger than the reserve level, rendering the currency board unsustainable, the government will also delink immediately.

If the money demand contraction shock is less than or equal to $R$, then whether to uphold the currency board system is a policy decision of the government that takes into account of the tradeoff between the maintaining cost and the abandonment cost. The government's decision is to minimize the social loss function. If the link is maintained, any change in the domestic money supply will be absorbed by the foreign reserve holdings of the government, $\Delta R=-S$.

The social loss from the point of view of the government when the currency board is maintained is in terms of the political pain arising from a respondent (to the external shock) decrease in production and increase in unemployment, plus the loss in the economic value associated with a lower reserve level after the shock. We assume that it is proportional to the size of money demand contraction shock and it is given as

$$
L^{L}=a \times S \quad \text { for all } S>0
$$

where $a>g>0^{14}$

The parameter " $a$ " summarizes many relevant features of the underlying economy. A country adopting a currency board loses control over its monetary policy and exchange rate and thus it must rely on the flexibility of its wage and price structures and its ability to use fiscal policies to absorb economic shocks. Take Argentina and Hong Kong as examples. Hong Kong has a flexible economy and labor market, and a huge government surplus. When the neighboring countries were devaluing their currencies in 1997-98, prices and wages in Hong Kong fell and the government was able to spend part of its huge surplus to absorb some of the shocks. In this sense, the parameter " $a$ " for Hong Kong would be relatively small. On the other hand, after the devaluations of the Mexican peso in 1995 and the Brazilian real in 1999, the wage and price

\footnotetext{
${ }^{14}$ To keep the model simple, the loss function is assumed to be linear and therefore the expected loss function is quadratic. The general intuition of the model would not change much if we assume $L^{L}$ to be a well-behaved function increasing in $S$. The inequality, $a>g$, arises because in order to keep the currency board, there would be a loss in the economic fundamentals of at least $(g \times S)$ [in Equation 5] corresponding to a loss of $S$ in reserves.
} 
structures in Argentina remained rigid and increasingly uncompetitive. Argentina had one of the largest emerging market debts and ran fiscal deficits aggravated by political bickering international investors were increasingly reluctant to keep lending to Argentina for its fiscal spending (impaired debt capacity). The Argentine currency board prevented Argentina from financing fiscal deficits with printing money. Consequently, Argentina went into a recession with unemployment skyrocketed to more than 18 percent and ultimately led to deadly riots in December 2001. In our model, the parameter " $a$ ” for Argentina would be relatively large.

The social cost of abandoning the currency board arrangement, on the other hand, includes a renege cost, $X$, and a cost arising from the decrease in the present value of the fundamental value of the economy when the currency is delinked:

$$
L^{D}=X+\left(f_{L}-f_{D}\right)
$$

The renege cost can be interpreted as a perceived cost arising from losing future credibility of the government and losing the credibility of any future fixed exchange rate commitments that may be necessary to guarantee domestic price stability. The renege cost includes also the damage to the country's financial system when a currency board collapses. In addition, the government may also lose future access to the international capital markets. The Argentine government obviously did not take the renege cost lightly as it risked mounting social unrest to continue its currency board until late in 2001. We can interpret the parameter $X$ as a reflection of the determination of government in maintaining the existing currency board system.

Therefore, the government will trade off the maintaining cost (higher unemployment, lower production, loss of reserve) against the abandonment cost (increase in exchange rate volatility and investment risk premium, loss of credibility, ensuring financial chaos, loss in the domestic economic fundamental after delink) in deciding whether to voluntarily abandon the currency board. A government with a high $X$ is the one who regards its credibility to be vital to the confidence of its people and international investors, and regards the continuation of its currency board vital to the stability of its financial system. It would want to maintain the currency board even at a high political cost. 


\subsection{Maximum level of Foreign Reserve Used by the Government}

At $t=0$, to deduce the probability of devaluation at $t=1$, we must first analyze the strategic decision of the government at $t=1$. If the money demand contraction shock $S$ is less than the foreign reserve level $R$, the government has a choice to abandon the currency board or not. If $a \times R \leq X+\left(f_{L}-f_{D}\right)$ (i.e., the abandonment cost is higher than the maintaining cost even when the shock is as large as the total reserves), the government will not voluntarily abandon the currency board. As such, the problem becomes trivial because $p^{*}, R$ and the distribution of $S$ completely determine whether there is a panic run against the currency board at $t=0$.

The more interesting case is when $a \times R>X+\left(f_{L}-f_{D}\right)$. In this case, the government may voluntarily abandon the currency board even though it has enough ability (foreign reserve) to maintain it. Our remaining analysis will concentrate on the more interesting case of $a \times R>X+\left(f_{L}-f_{D}\right)$.

Let $z^{*}$ be the maximum amount of shock the government is able and willing to absorb without delinking (where $0 \leq z^{*} \leq R$ ).

\section{Proposition (I)}

With perfect information about $X$, there exists a critical value for $X$, call it $\bar{X}$, such that $z^{*}$ is given as follows:

Case [1]: $\quad$ If $\quad 0 \leq X \leq \bar{X}$,

$$
\begin{aligned}
& z^{*}=\left(\frac{X+\left(f_{L}-f_{D}\right)}{a}\right) \\
& \text { where } \bar{X}=\left[a \times R-\left(f_{L}-f_{D}\right)\right] .
\end{aligned}
$$

Case [2]: If $\bar{X}<X, z^{*}=R$. Hence, a government with determination higher $\operatorname{than} \bar{X}$ will never voluntarily delink.

Proof: Appendix A.1

Given $z^{*}$, we can write down the probability of delink, $p$, as 


$$
p=P\left\{S>z^{*}\right\}=\left[\frac{(\alpha+\beta) \times M-z^{*}}{2 \beta M}\right]
$$

where $z^{*}=\left\{\begin{array}{cc}{\left[\frac{X+\left(f_{L}-f_{D}\right)}{a}\right]} & \text { if } \frac{X+\left(f_{L}-f_{D}\right)}{a} \leq R \\ R & \text { otherwise }\end{array}\right.$

\section{Figures 3a and $3 \mathrm{~b}$ about here}

We can now derive the critical point $\left(X_{\text {Safe }}^{p^{*}}\right)$ defined as the minimum level of government determination (given $p^{*}$ ) which will not induce a run against the currency board at $t=0$,

\section{Figure 4 about here}

To derive the critical value $X_{\text {Safe }}^{p^{*}}$, we consider the following three possible cases:

[a] If $\quad p^{*}<\left[\frac{(\alpha+\beta) \times M-R}{2 \beta M}\right]$ which is the probability of delink when $z^{*}=R$,

the currency board will collapse immediately because even if the government is willing to exhaust all its reserves to support the currency board, the probability of delink is still too high.

[b] If $\quad\left[\frac{a \times(\alpha+\beta) \times M-\left(f_{L}-f_{D}\right)}{2 a \beta M}\right] \leq p^{*}$,

there is no panic run against the currency board for any government (because the shock is expected to be small and the cost of absorbing the shock is expected to be small relative to the benefit of keeping the link; the critical point is found by solving for $p$ at $X=0$ ).

[c] If $\quad\left[\frac{(\alpha+\beta) \times M-R}{2 \beta M}\right] \leq p^{*}<\left[\frac{a \times(\alpha+\beta) \times M-\left(f_{L}-f_{D}\right)}{2 a \beta M}\right]$,

we can solve for $X_{\text {Safe }}^{p^{*}}$. Let $p=p^{*}$, where $p$ is given in the (0). We have

$$
X_{\text {Safe }}^{p^{*}}=\left\{a M \times\left[\beta \times\left(1-2 p^{*}\right)+\alpha\right]-\left(f_{L}-f_{D}\right)\right\}
$$


(i) For a government with $X$ higher than or equal to $X_{\text {Safe }}^{p^{*}}$, the public will realize that $p \leq p^{*}$. Hence, there is no panic selling.

(ii) For a government with $X$ lower than $X_{\text {Safe }}^{p^{*}}$, the public will realize that $p>p^{*}$. Hence, the public will run the currency board and the currency board collapses at $t=0$. In this case, it may be in the interest of the government to use a foreign reserve commitment policy (discussed in next section) to reduce its delink probability and avert the public's panic run against the currency board.

To summarize, in the case of symmetric information (between the government and the public) about the government's determination, $X$, and no explicit reserve commitment by the government to back the currency board, the public assesses the devaluation probability conditional on the distribution of $S$ and $X$. If $p>p^{*}$, the public will (uncoordinatedly, as in a bank run) panic-sell to protect itself. Realizing the currency board is unsustainable, the government will abandon the currency board immediately to preserve the foreign currency reserves. On the other hand, if $p \leq p^{*}$, there will not be a panic run against the currency board at $t=0$.

\section{An Irrevocable Foreign Reserve Commitment Policy}

CCM propose an irrevocable foreign reserve commitment policy to enhance the stability of currency board system. Under the proposed reserve commitment policy, a government must continue to honor any conversion demand for foreign currency for at least up to its commitment level at the pre-specified exchange rate of the currency board no matter whether the government decides to maintain, or strategically or involuntarily abandon the currency board. The main purpose of the policy is to eliminate certain bad equilibriums. As the reserve commitment policy is actually a binding contract for the future action of the government, the public understands that the government is less likely to abandon the currency board system after engaging in the commitment, and hence their confidence on the continuation of the currency board increases. In this section, we analyze the merits of the policy within our theoretical framework for currency boards. 
The irrevocable foreign reserve commitment policy can be provided in the form of a typical currency put option (with an independent trustee), an exchange rate insurance or other variations. $\frac{15}{15}$ The commitment policy is not costless in the sense that if the currency board is ultimately abandoned, the reserve level will fall by an amount equal to the commitment level. Given the fact that a government wants to minimize the drain of foreign currency reserves, it will suspend the linked exchange rate immediately after it decides to abandon the currency board (no matter strategically or involuntarily) and limit the loss of foreign reserves only to its committed level.

\section{Figure 5 about here}

Let us now analyze the case where the government makes an irrevocable reserve commitment of $C$ to guarantee the currency board. The social loss functions are as follows:

The social loss for maintaining a currency board system (given a commitment of $C$ ) remains as

$$
L_{C}^{L}=a \times S \quad \text { for all } S>0
$$

On the other hand, the cost of abandoning the currency board arrangement includes a renege cost, $X$, a cost arising from the decrease in the present value of the fundamental value of the economy when the currency is delinked, plus a new cost arising from the decrease in the foreign reserves under the reserve commitment policy. It becomes

$$
L_{C}^{D}=X+\left(f_{L}-f_{D}\right)+g \times C
$$

Given a foreign reserve commitment level $(C)$, let $z_{C}^{*}$ be the maximum shock the government is able and willing to absorb without delinking (where $0 \leq z_{C}^{*} \leq R$ ).

\footnotetext{
${ }^{15}$ A government can issue a limited amount of domestic currency put option to the public with an exercise price equal to the official linked exchange rate under the currency board. One weakness of this arrangement is that a government may default on the put option contract as well (refuses to sell foreign currency at the official linked exchange rate to put option holders) after it defaults on its currency board. To guarantee performance, the monetary authority would have to deposit the guarantee with a third party, as in the case of Brady bonds where the guaranteed principal is deposited with a trustee in the U.S. An alternative is an exchange rate insurance in a special form of foreign reserve lending facility contained in the proposal to the Hong Kong Financial Secretary on November 14, 1997 and reported in Chan and Chen (1999). In that proposal, licensed banks would be able to borrow a limited amount (equal to the size of the put option) of the reserve currency and have the option to repay in domestic currency (at the linked exchange rate of the currency board). As the put option holders have already received the underlying foreign currency, the government cannot unilaterally default on the put option under this special arrangement. Alternatively, the put option can also be integrated into structured notes as exchange rate insurance, as in Merton Miller's proposal to the Premier of China in 1998 (See South China Morning Post, January 20, 1998). The scheme that was finally adopted by the Hong Kong Monetary Authority in September of 1998 was a combination of the last two variations.
} 


\section{Proposition (II)}

With perfect information and foreign reserve commitment, $C$, the maximum shock the government is able and willing to absorb without delinking, $z_{C}^{*}$, is as follows:

Case [1]: $\quad$ If $\quad 0 \leq X \leq \bar{X}_{C}$,

$$
\begin{aligned}
& z_{C}^{*}=\left(\frac{X+\left(f_{L}-f_{D}\right)+g \times C}{a}\right) \\
& \text { where } \bar{X}_{C}=(a \times R-g \times C)-\left(f_{L}-f_{D}\right) .
\end{aligned}
$$

Case [2]: If $\quad \bar{X}_{C} \leq X$,

$$
z_{C}^{*}=R
$$

Proof: Appendix A.2.

$\bar{X}_{C}$ is the upper critical value for $X$ under the foreign reserve commitment policy $C$. A government with reserve commitment $C$ and weak determination $\left(X\right.$ less than $\left.\bar{X}_{C}\right)$ chooses to strategically delink after paying off $C$ if the money demand contraction shock is more than $z_{C}^{*}$. On the other hand, a government with commitment $C$ and strong determination ( $X$ greater than $\bar{X}_{C}$ ) will never voluntarily delink. The upper critical value, $\bar{X}_{C}$, is decreasing with $C$ because $\frac{\partial \bar{X}_{C}}{\partial C}=-g<0$

\section{Figures $6 a$ and $6 b$ about here}

3 1 Conditional Probability of Delink

Conditional on the reserve commitment policy $C$, let $p_{C}$ be the conditional probability of delink. We have,

$$
p_{C}=\operatorname{Prob}\left\{S>z_{C}^{*} \mid \operatorname{commit} C\right\}=\left[\frac{(\alpha+\beta) \times M-z_{C}^{*}}{2 \beta M}\right]
$$


where $z_{C}^{*}=\left\{\begin{array}{ccc}{\left[\frac{X+\left(f_{L}-f_{D}\right)+g \times C}{a}\right]} & \text { if } & \frac{X+\left(f_{L}-f_{D}\right)+g \times C}{a} \leq R \\ R & \text { if } & \frac{X+\left(f_{L}-f_{D}\right)+g \times C}{a}>R\end{array}\right.$

In other words, for a given $X$, the higher the commitment $C$, the less likely the government will delink voluntarily (because $z_{C}^{*}$, the amount of shock the government is willing to absolve without delinking, is higher). At high enough $C$, it is possible that the government would never voluntarily delink (as the critical value $\bar{X}_{C}$ decreases with $C$ ).

3.2 Optimal Reserve Commitment $C^{p^{*}}(X)$

Next, we derive the optimal reserve commitment, $C^{p^{*}}(X)$, such that a government with determination $X$, which is less than $X_{\text {Safe }}^{p^{*}}$ (and within the relevant range discussed in Section 2.5, case [c]), can avoid a collapse of the currency board at $t=0$ if the government is willing to commit at least $C^{p^{*}}(X)$. As the committed reserve level must be non-negative and not greater than the available reserve level $R$, the existence of solution for $C^{p^{*}}$ depends on $X, R$ and other parameters. To derive the function $C^{p^{*}}(X)$, we consider the following three different cases:

(i) If $\quad X_{\text {Safe }}^{p^{*}} \leq X, \quad C^{p^{*}}=0$.

This is a result derived in Section 2. WWhen $X$ is high, a public panic run will not happen even if the government does not commit any foreign reserve.

(ii) If $X<X_{\text {Run }}^{p^{*}}$, where $X_{\text {Run }}^{p^{*}}=\left\{a M \times\left[\beta \times\left(1-2 p^{*}\right)+\alpha\right]-g \times R-\left(f_{L}-f_{D}\right)\right\}$, there is no feasible solution for $C^{p^{* 46}}$. When $X$ is too low and $R$ is not sufficient, the currency board would collapse even if the government commits all available foreign reserve.

\footnotetext{
${ }^{16}$ To see that, for $X<X_{R u n}^{p^{*}}$, we can expand the formula of $p_{C}$ as follows:
} 
(iii) If $\quad X_{\text {Run }}^{p^{*}} \leq X<X_{\text {Safe }}^{p^{*}}, \quad C^{p^{*}}=\left\{\frac{a M \times\left[\beta \times\left(1-2 p^{*}\right)+\alpha\right]-X-\left(f_{L}-f_{D}\right)}{g}\right\}$.

To avoid the public's panic run at the lowest social cost, a government would like to use minimum level of reserve so that the conditional probability of delink (conditional on commitment $C$, i.e., $p_{C}$ ) is not larger than the public's maximum tolerance $p^{*}$. It will commit $C^{p^{*}}$ such that $p_{C}=p^{*}$.

$$
\begin{aligned}
p^{*} & =p_{C=C^{p^{*}}} \\
& =\operatorname{Prob}\left\{S>z_{C}^{*} \mid \operatorname{commit} C=C^{p^{*}}\right\} \\
& =\left[\frac{(\alpha+\beta) \times M-z_{C}^{*}}{2 \beta M}\right] \\
& =\left\{\frac{(\alpha+\beta) \times M-\left[\frac{X+\left(f_{L}-f_{D}\right)+g \times C^{p^{*}}}{a}\right]}{2 \beta M}\right\}
\end{aligned}
$$

or

$2 \beta M p^{*}=\left\{(\alpha+\beta) \times M-\left[\frac{X+\left(f_{L}-f_{D}\right)+g \times C^{p^{*}}}{a}\right]\right\}$

Hence, $C^{p^{*}}=\left\{\frac{a M \times\left[\beta \times\left(1-2 p^{*}\right)+\alpha\right]-X-\left(f_{L}-f_{D}\right)}{g}\right\}$

It is straightforward to verify that for all $X_{\text {Run }}^{p^{*}} \leq X<X_{\text {Safe }}^{p^{*}}, 0 \leq C^{p^{*}} \leq R$. Hence, the solution of $C^{p^{*}}$ exists. Furthermore, as a government will minimize the potential

$$
\begin{aligned}
p_{C} & =\operatorname{Prob}\left\{S>z_{C}^{*} \mid \text { commit } C\right\}=\left[\frac{(\alpha+\beta) \times M-z_{C}^{*}}{2 \beta M}\right] \\
& =\left[\frac{(\alpha+\beta) \times M-\left[\frac{X+\left(f_{L}-f_{D}\right)+g \times C}{a}\right]}{2 \beta M}\right]>\left[\frac{(\alpha+\beta) \times M-\left[\frac{X_{R u n}^{p^{*}}+\left(f_{L}-f_{D}\right)+g \times C}{a}\right]}{2 \beta M}\right]=p^{*}+\left[\frac{g \times(R-C)}{2 a \beta M}\right] \geq p^{*}
\end{aligned}
$$

for all $C \leq R$.

Hence, $p_{C}>p^{*}$ and a public's panic run is unavoidable. 
social loss through using the minimum level of reserve which can avert the panic run, the solution of $C^{p^{*}}$ is also unique.

\section{Figure 7 about here}

To summarize, for a government with determination $X$ less than $X_{R u n}^{p^{*}}$, a panic run is unavoidable with any commitment policy given the available foreign reserve level. For a government with determination $X$ higher than $X_{\text {Safe }}^{p^{*}}$, it does not have to commit any foreign reserve and there is no panic run. For a government with $X$ in between $\left(X_{R u n}^{p^{*}}, X_{\text {Safe }}^{p^{*}}\right)$, the foreign reserve commitment policy, $C^{p^{*}}$, is a decreasing function of $X$. A government with a higher determination $(X)$ can use less foreign reserve commitment to avert a panic run against the currency board.

The optimal commitment level $C^{p^{*}}$ is intuitively link to the critical probability $p^{*}$. If the public's tolerance level for the exchange rate risk, $p^{*}$, is high. A government can avert a run by using a low reserve commitment $C^{p^{*}}$ or even no reserve commitment. In times of confidence crisis, however, the public may panic easily and the critical value of the public's tolerance level for exchange rate risk, $p^{*}$, is low. A government would have to use a high reserve commitment $C^{p^{*}}$ to avert a panic run against the currency board. Hence, the role of reserve commitment policy in restoring the public confidence becomes more important in times of crisis.

$3 \sqrt{3}$ To Commit $C^{p^{*}}(X)$ or not when $X_{\text {Run }}^{p^{*}} \leq X<X_{\text {Safe }}^{p^{*}}$

Next, we compare the social loss perceived by a government with $X$, which is less than $X_{\text {Safe }}^{p^{*}}$ but not less than $X_{\text {Run }}^{p^{*}}$, between the choice of committing $C^{p^{*}}(X)$ to avert panic runs at $t=0$ versus the choice of not committing any reserve. It follows from the analysis above that the gain from using reserve commitment $C^{p^{*}}$ to avert the public's panic run is 


$$
\begin{aligned}
G\left(X, p^{*}\right)= & \left\{E[L \mid C=0, \text { with Public's Panic Run }]-E\left[L \mid C=C^{p^{*}}, \text { No Public's Panic Run }\right]\right\} \\
= & {\left[X+\left(f_{L}-f_{D}\right)\right] } \\
& -\left\{p^{*} \times\left[X+\left(f_{L}-f_{D}\right)+g \times C^{p^{*}}\right]+\left(1-p^{*}\right) \times\left[\left(\frac{a}{2 \times\left[z_{C}^{p^{*}}-(\alpha-\beta) \times M\right]}\right) \times\left(z_{C}^{p^{*}}\right)^{2}\right]\right\}
\end{aligned}
$$

and it is an increasing function with $X$ under perfect information (see Appendix A.3). If

$G\left(X, p^{*}\right)>0$, it would be in the interests of the government to make an irrevocable commitment of $C^{p^{*}}(X)$ to avert runs at $t=0$. Otherwise, the government is better off not to commit and just let the currency board collapse immediately.

\section{Figure 8 about here}

For a government with high determination $(X)$, using $C^{p^{*}}$ can reduce its social loss because it can avoid the high perceived renege cost in the event of abandoning the currency board. On the other hand, for a government with very low determination $(X)$, it may be better not to commit any reserve to avoid the public's panic run because its perceived renege cost from abandoning the currency board is too low relative to the expected social cost arising from the inflexibility in abandoning currency board from the commitment policy.

Let's define $X_{\text {Indiff }}^{p^{*}}$ as the critical value of determination such that a government with $X_{\text {Indiff }}^{p^{*}}$ is indifferent to abandoning the currency board versus averting the public's panic run by committing $C^{p^{*}}$. Thus, $X_{\text {Indiff }}^{p^{*}}$ is the $X$-intercept for $G\left(X, p^{*}\right)$ [i.e., $G\left(X_{\text {Indiff }}^{p^{*}}, p^{*}\right)=0$, see figure 8]. The existence of such a solution within the relevant range depends on the parameter values of the model. The following are the exhaustive cases: (a) If there exists a solution for $X_{\text {Indiff }}^{p^{*}}$ between $X_{\text {Run }}^{p^{*}}$ and $X_{\text {Safe }}^{p^{*}}$, it is unique (because $\frac{\partial G}{\partial X}>0$ from Appendix A.3) and a government with $X$ such that $X_{\text {Indiff }}^{p^{*}} \leq X<X_{\text {Safe }}^{p^{*}}$ will commit $C^{p^{*}}(X)$ while a government with $X_{\text {Run }}^{p^{*}} \leq X<X_{\text {Indiff }}^{p^{*}}$ will abandon the currency board immediately at $t=0$. (b) If $G\left(X, p^{*}\right)>0$ for all $X_{R u n}^{p^{*}} \leq X<X_{\text {Safe }}^{p^{*}}$, the gain from commitment is positive within the relevant range of $X$. All governments with $X$ less than $X_{\text {Safe }}^{p^{*}}$ but not less than $X_{\text {Run }}^{p^{*}}$ will commit their respective $C^{p^{*}}(X)$ to avoid the panic run at 
$t=0$. Finally, (c) if $G\left(X, p^{*}\right)<0$ for all $X_{\text {Run }}^{p^{*}} \leq X<X_{\text {Safe }}^{p^{*}}$, no government will commit any reserve, and all governments with $X$ less than $X_{\text {Safe }}^{p^{*}}$ will abandon the currency board at $t=0$.

Thus, given $X$ and $p^{*}$, the government assesses $G\left(X, p^{*}\right)$. If $G\left(X, p^{*}\right)$ is non-positive, the government would not make any commitment and the currency board would collapse immediately. If $G\left(X, p^{*}\right)$ is positive, the government would make an optimal commitment of $C^{p^{*}}(X)$ to avert a panic run at $t=0$ and the currency board would not collapse.

\section{Reserve Commitment under Asymmetric Information}

Suppose that the government's determination to maintain the currency board is known to the government but not to the public. If the public underestimates the determination of government, what can the government do to improve its social welfare under this information asymmetry? This section examines how a government can use an explicit reserve commitment policy to signal its true determination to maintain the currency board, whereby reducing the social loss arising from the information asymmetry between the government and the public.

\subsection{Optimal Reserve Commitment under Information Asymmetry}

Suppose there are two types of governments, $\mathrm{L}$ and $\mathrm{H}$, and let $X_{L}$ and $X_{H}$ denote their respective values of the government's determination to maintain the currency board, where $X_{L}<X_{H}$. The government knows that it is an H-type, but the public underestimates the

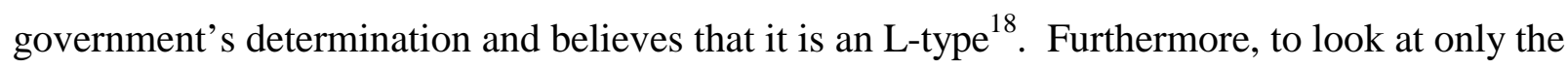
non-trivial cases, we assume that (1) $X_{L}<X_{\text {Safe }}^{p^{*}} 1$ which means that the currency board will collapse if the government does not commit any foreign reserve and the public believe its

\footnotetext{
${ }^{17}$ Or equivalently, a government can signal its private information on the magnitude of negative impact on economic fundamental from delink, $\left(f_{L}-f_{D}\right)$, if this is not public information.

${ }^{18}$ It is trivial to consider the case when the market overestimates the determination of the government to maintain the currency board. If the market overestimates the government's determination value $X_{H H}$, which is larger than the actual determination value $X_{H}$, the government with determination $X_{H}$ can simply use $C^{p^{*}}\left(X_{H H}\right)$, which is not greater than $C^{p^{*}}\left(X_{H}\right)$, to avert the public's panic runs.

${ }^{19}$ It is trivial to consider $X_{L} \geq X_{\text {Safe }}^{p^{*}}$ because both the government with $X_{H}$ and the government with $X_{L}$ can avoid the public's panic run without any reserve commitment.
} 
determination value to be $X_{L}$ and (2) $X_{L}<\left[a \times R-\left(f_{L}-f_{D}\right)\right]$, which means that a government with $X_{L}$ may voluntarily delink even if the external shock is less than $R$. Both the government and the public know the two possible levels; however, only the government knows that its true value is $X_{H}$. Given $p^{*}$, let us consider a government with $X_{H}$, which is greater than $X_{R u n}^{p^{*}}$ and $X_{\text {Indiff }}^{p^{*}}$. Hence, $X_{H}$ can reduce its social loss if it could reveal its true determination to the public. Can a government with $X_{H}$ signal to the public by a reserve commitment policy to avert an immediate collapse of the currency board and what should the optimal reserve commitment level be?

Consider a government with $X_{H}$ who wants to use a reserve commitment policy to induce a separating equilibrium and avert the public's panic run. The optimal commitment level cannot be less than $C_{H}^{p^{*}}$, which is the optimal (minimum) reserve commitment for $X_{H}$ under perfect information. In other words, $C_{H}^{p^{*}}$ is the lower bound of optimal reserve commitment for $X_{H}$ under imperfect information (with $X_{L}<X_{H}$ ). If the lower bound of reserve commitment, $C_{H}^{p^{*}}$, can effectively change the public's pessimistic estimate of the government's determination from $X_{L}$ to $X_{H}$, it means that a government with $X_{L}$ committing $C_{H}^{p^{*}}$ will incur a higher expected social loss than not committing any reserve (i.e. $C=0$ ). To analyze whether a government with $X_{L}$ will imitate the government with $X_{H}$ through committing $C_{H}^{p^{*}}$, we have to examine its benefit from imitation.

The gain for $X_{L}$ to imitate $X_{H}$ can be written as:

$$
\begin{aligned}
& G I\left(X_{L}, X_{H}\right) \\
& =\left[X_{L}+\left(f_{L}-f_{D}\right)\right] \\
& \quad-\left\{p_{C_{H}^{p^{*}}}^{L} \times\left[X_{L}+\left(f_{L}-f_{D}\right)+g \times C_{H}^{p^{*}}\right]+\left(1-p_{C_{H}^{p^{*}}}^{L}\right) \times\left[\left(\frac{a}{2 \times\left[z_{C_{H}^{p^{*}}}^{L}-(\alpha-\beta) \times M\right]}\right) \times\left(z_{C_{H}^{p^{*}}}^{L}\right)^{2}\right]\right\}
\end{aligned}
$$

\footnotetext{
${ }^{20}$ It is trivial to consider $X_{L} \geq\left[a \times R-\left(f_{L}-f_{D}\right)\right]$ because both the government with $X_{H}$ and the government with $X_{L}$ will not voluntarily delink.

${ }^{21}$ It is trivial to consider $X_{H}<X_{R u n}^{p^{*}}$ because both the government with $X_{H}$ and the government with $X_{L}$ cannot avoid the public's panic run by commitment policy.
} 
with $p_{C_{H}^{p^{*}}}^{L}=\left[\frac{(\alpha+\beta) \times M-z_{C_{H}^{p^{*}}}^{L}}{2 \beta M}\right]$ and $z_{C_{H}^{p^{*}}}^{L}=\min \left\{\left(\frac{X_{L}+\left(f_{L}-f_{D}\right)+g \times C_{H}^{p^{*}}}{a}\right), R\right\}$.

The first term is the loss from delink and the second term is the expected loss from mimicking. Thus the difference is the expected gain from mimicking. The following proposition shows that for sufficiently small $X_{L}$, the L-type will not mimic the H-type.

\section{Proposition (III): $\quad$ Reserve Commitment $\left(C_{H}^{p^{*}}\right)$ with Separating Equilibrium}

There exists $X^{\#}$ such that for any $X_{L}<X^{\#}$, a government with $X_{H}$ can use the reserve commitment policy $C_{H}^{p^{*}}$ to signal its true type to the public and reduce its social loss; where $C_{H}^{p^{*}}$ is the optimal reserve commitment of $X_{H}$ to avert a panic run under perfect information; and $X^{\#}$ is the highest value of $X_{L}$ such that a government with $X_{L}$ will not imitate $X_{H}$ by committing $C_{H}^{p^{*}}$. The critical value, $X^{\#}$, is the unique solution from the equation

$$
G I\left(X^{\#}, X_{H}\right)=0
$$

if a solution exists for $0<X^{\#}<X_{H}$. Otherwise, $G I\left(X_{L}, X_{H}\right)>0$ for all $X_{L}, 0<X_{L}<X_{H}{ }^{22}$. In this case, define $X^{\#}=0$. It means that $X_{H}$ cannot generate any separating equilibrium by committing just $C_{H}^{p^{*}}$. For an H-type to separate from the L-type, the H-type must commit more than $C_{H}^{p^{*}}$.

Proof: Appendix A.4.

\section{Figure 9 about here}

For any $X_{L} \geq X^{\#}$, a government with $X_{H}$ cannot simply use the reserve commitment policy, $C_{H}^{p^{*}}$, to separate itself from a government with $X_{L}$. In this case, $X_{H}$ would have to commit more to avert a run against its currency board. Let us define $C_{L}^{\text {Indiff }}$ to be the maximum reserve commitment such that $X_{L}$ is willing to commit if such commitment will avert a public panic run. The value of $C_{L}^{\text {Indiff }}$ can be solved from the following equation: 


$$
\begin{aligned}
& G\left(X_{L}, C=C_{L}^{\text {Indiff }}\right)
\end{aligned}
$$

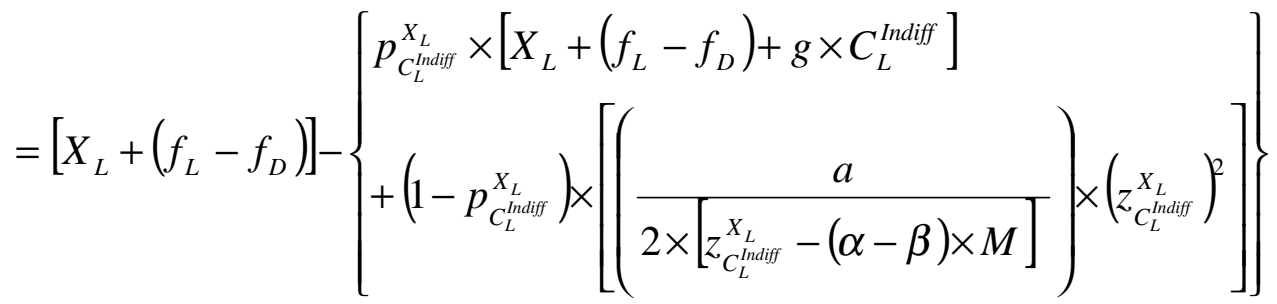

$=0$

with $p_{C_{L}^{\text {lndiff }}}^{X_{\text {lif }}}=\left[\frac{(\alpha+\beta) \times M-z_{C_{L}^{\text {lndiff }}}^{X_{L}}}{2 \beta M}\right]$ and $z_{C_{L}^{\text {Indiff }}}^{X_{1}}=\min \left\{\left(\frac{X_{L}+\left(f_{L}-f_{D}\right)+g \times C_{L}^{\text {Indiff }}}{a}\right), R\right\}$.

If the solution of $[17)$ is between 0 and $R$, the solution of $C_{L}^{\text {Indiff }}$ is unique (see Appendix A.5). Otherwise, $G\left(X_{L}, C\right)>0$ for all $0 \leq C \leq R .{ }^{3}$ It means that a government with $X_{L}$ has an incentive to avert a collapse of its currency board even by committing all reserve $R$. In this case, we define $C_{L}^{\text {Indiff }}=\infty$ for the purpose of Proposition IV below.

Similarly, we define $C_{H}^{\text {Indiff }}$ to be the maximum reserve that a government with $X_{H}$ is willing to commit if such commitment will avert a public panic run. The value of $C_{H}^{\text {Indiff }}$ is solved from the following equation:

$$
\begin{aligned}
& G\left(X_{H}, C=C_{H}^{\text {Indiff }}\right) \\
& =\left[X_{H}+\left(f_{L}-f_{D}\right)\right]-\left\{\begin{array}{l}
p_{C_{H}^{X_{H}}}^{X_{\text {diff }}} \times\left[X_{H}+\left(f_{L}-f_{D}\right)+g \times C_{H}^{\text {Indiff }}\right] \\
+\left(1-p_{C_{H}^{\text {Indiff }}}^{X_{H}}\right) \times\left[\left(\frac{a}{2 \times\left[z_{C_{H}^{\text {Indiff }}}^{X_{H}}-(\alpha-\beta) \times M\right]}\right) \times\left(z_{C_{H}^{X_{H}}}^{X_{\text {ndiff }}}\right)^{2}\right]
\end{array}\right\}
\end{aligned}
$$

$$
=0
$$

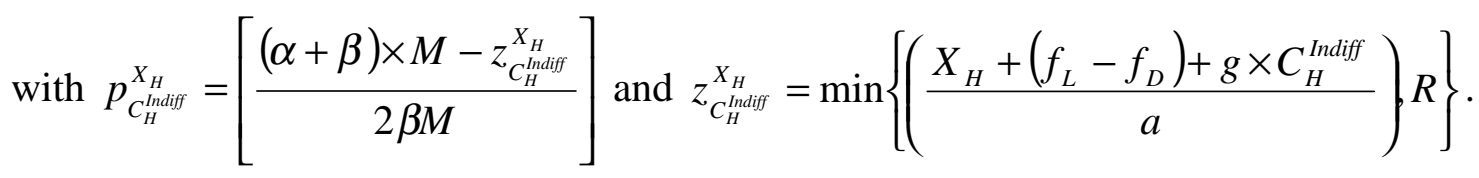

${ }^{22} G I\left(X_{L}, X_{H}\right)$ cannot be negative for all $X_{L}, 0<X_{L}<X_{H}$ because $X_{H}>X_{\text {Indiff }}^{p^{*}}$.

${ }^{23}$ As we are considering $X_{L} \geq X^{\#}$, it is impossible that $G\left(X_{L}, C\right)<0$ for all $0 \leq C \leq R$. 
If the solution of (18) is between 0 and $R$, the solution of $C_{H}^{\text {Indiff }}$ is unique (see Appendix A.5). Otherwise, $G\left(X_{H}, C\right)>0$ for all $0 \leq C \leq R{ }^{24}$ It means that a government with $X_{H}$ has an incentive to avert panic runs even by committing all reserve $R$. In this case, define $C_{H}^{\text {Indiff }}=\infty$ for the purpose of Proposition IV below.

Finally, define $C_{L}^{p^{*}}=\left\{\frac{a M \times\left[\beta \times\left(1-2 p^{*}\right)+\alpha\right]-X_{L}-\left(f_{L}-f_{D}\right)}{g}\right\}$. From Section 3.2, $C_{L}^{p^{*}}$ has the interpretation that it is the commitment of a government with $X_{L}$ that would avert runs. If $C_{L}^{p^{*}}>R$, it is not a feasible commitment, but the value $C_{L}^{p^{*}}$ is still useful for delineating the cases in the proposition below. The following propositions list all the possible equilibriums.

\section{Proposition (IV.a): Reserve Commitment ( $C_{L}^{\text {Indiff }}$ ) with a Separating Equilibrium}

For any $X_{L} \geq X^{\#}$, if $\min \left\{C_{L}^{p^{*}}, C_{L}^{\text {Indiff }}\right\} \leq \min \left\{R, C_{H}^{\text {Indiff }}\right\}$ and $C_{L}^{\text {Indiff }}<C_{L}^{p^{*}}$, a government with $X_{H}$ can adopt the optimal reserve commitment policy ( $C_{L}^{\text {Indiff }}$ ) to separate itself from $X_{L}$ and reduce its social loss. A separating equilibrium is reached such that the public's estimate of its determination is upgraded and there is no panic run.

Proof: When an H-type commits any amount above $C_{L}^{\text {Indiff }}$, the L-type will rather allow its currency board to collapse than to mimic (from the definition of $C_{L}^{\text {Indiff }}$ ). Thus there is a separating equilibrium.

\section{Proposition (IV.b): $\quad$ Reserve Commitment $\left(C_{L}^{p^{*}}\right)$ with a Good Pooling Equilibrium}

For any $X_{L} \geq X^{\#}$, if $\min \left\{C_{L}^{p^{*}}, C_{L}^{\text {Indiff }}\right\} \leq \min \left\{R, C_{H}^{\text {Indiff }}\right\}$ and $C_{L}^{p^{*}} \leq C_{L}^{\text {Indiff }}$, a government with $X_{H}$ can adopt the optimal reserve commitment policy $\left(C_{L}^{p^{*}}\right)$ to reduce its social loss. A good pooling equilibrium is reached where there is no panic run, even though the public cannot tell whether the government is of L-type or H-type.

Proof: As $C_{L}^{p^{*}} \leq C_{L}^{\text {Indiff }}$, a L-type is willing to commit $C_{L}^{p^{*}}$ to avert runs. As

$C_{L}^{p^{*}} \leq \min \left\{R, C_{H}^{\text {Indiff }}\right\}$, the H-type is willing and able to commit $C_{L}^{p^{*}}$ to avert run also.

\footnotetext{
${ }^{24}$ As we are considering $X_{H}>X_{L} \geq X^{\#}$, it is impossible that $G\left(X_{H}, C\right)<0$ for all $0 \leq C \leq R$.
} 
Note: In this case, the H-type may still be able to induce a separating equilibrium by committing more, but this would not be in its interest as the H-type can commit a lower amount, pool with the L-type and can still avert a run.

\section{Proposition (IV.c): No Reserve Commitment with a Bad Pooling Equilibrium}

For any $X_{L} \geq X^{\#}$, if $\min \left\{C_{L}^{p^{*}}, C_{L}^{\text {Indiff }}\right\}>\min \left\{R, C_{H}^{\text {Indiff }}\right\}$, a government with $X_{H}$ cannot adopt any feasible reserve commitment policy to credibly distinguish itself from $X_{L}$ and a government with $X_{L}$ is unable to avert a run. Hence, the government will not commit any reserve and the currency board collapses immediately.

Proof: Since $C_{H}^{\text {Indiff }}>C_{L}^{\text {Indiff }}\left(\right.$ see Appendix A.6) $>\min \left\{R, C_{H}^{\text {Indiff }}\right\}$, therefore $\min \left\{R, C_{H}^{\text {Indiff }}\right\}=R$. Hence, $C_{L}^{p^{*}}>R$ and $C_{L}^{\text {Indiff }}>R$. As $C_{L}^{p^{*}}>R$, it implies the L-type cannot avert runs and its currency board would collapse. At the same time, $C_{L}^{\text {Indiff }}>R$ and therefore $\mathrm{H}$ does not have enough reserves (to commit more than $C_{L}^{\text {Indiff }}$ ) to credibly separate itself from L.

Consequently, we have a bad pooling equilibrium resulting in the immediate collapse of the currency board. $Q E D$

Proposition IV illustrates that there are different equilibriums depending on the market perception of the government's resolves. Consistent with simple economic intuition, if the market perception $\left(X_{L}\right)$ is close enough to the true government's resolves $\left(X_{H}\right)$ and the penalty of losing reserves is small, there is going to be a pooling equilibrium, as the government would not be able to use commitments to distinguish itself from the market misperception. On the other hand, if there is significant difference between the perceived resolves and the true resolves of the government, it is possible to induce a separating equilibrium and convince the market with reserve commitments. In the next section we will illustrate these implications from Proposition IV with examples pertaining to Hong Kong and Argentina.

\footnotetext{
${ }^{25}$ The implicit assumption is that the market expects the government to be definitely an L-type (an "Enron") unless the government can credibly signal that it is not. This assumption approximates the market sentiment in times of crisis when people are eager to protect the value of their life savings from devaluations. It is possible to impose a more complicated set of assumptions in our model, such as market prior expectations on the types ( $\mathrm{H}$ and $\mathrm{L}$ ) and posterior updates based on commitments, but we believe that our simple model adequately provides the appropriate representation of the market conditions under consideration.
} 


\subsection{Calibrations and implications}

It would be interesting to calibrate the parameters of our model to approximate the economic environment of the Hong Kong currency board during the East Asian and Russian financial crisis and the Argentine currency board just before it collapsed.

\subsubsection{The Hong Kong examples}

At the end of the summer of 1997, Hong Kong had about US\$86 billion in reserves and an M3 in Hong Kong dollar that was equivalent to US $\$ 210$ billion 2 . Accordingly, we set $M=20$ and $R=8$ in all the Hong Kong simulations below. During the crisis years of 1997-98, there were periods when Hong Kong actually experienced some capital inflows as Hong Kong was considered (relatively speaking) a safe haven when international investors moved their money out of the other neighboring countries ravaged by financial crises; and there were periods when the market sentiments in Hong Kong were fragile (e.g., after the Russian default) and the capital outflows from Hong Kong were significant. In the simulations below, we set $\alpha=0.05$ and $\beta=$ 0.4. We also set $\left(f_{L}-f_{D}\right)=1$, implying an immediate economic damage of $\$ 10$ billion if the currency board is delinked. We set the critical delink probability $p^{*}=0.1$, which implies that the local people will start a run against the currency board (in a manner resembling the case of Argentina in November 2001) if the perceived delink probability is higher than 0.1.

Figures 10a-c plot various scenarios corresponding to different parameters $\left(a, g, X_{H}\right)$ with the values of $X_{L}$ on the $\mathrm{X}$-axis. In our first example in figure 10a, we set $g=0.35$, which would imply a $\$ 0.35$ billion loss to the economic fundamental for every $\$ 1$ billion loss in reserves. We set $a=0.5$, which implies that if the currency board is maintained and the $\$ 1$ billion capital outflow shock is absorbed by the reserves, it induces an additional $\$ 0.15$ billion (based on $a$ - $g$, in addition to the damage arising from the loss of reserves based on $g$ ) of "economic loss" arising from the quantification of the government loss function associated with a rise in unemployment and a drop in production. We set a relatively low $a$ for Hong Kong, as Hong Kong's economy and labor market are quite flexible. The economy can easily adjust with some transitional pain in response to outside shocks. Finally, we set $X_{H}=3$ (a perceived renege cost of $\$ 30$ billion in the Hong Kong simulation) as the government's perceived damage of reneging on the currency board 
commitment. This parameter can be interpreted as the government's determination in maintaining the currency board as the government would tradeoff this perceived renege cost against the political cost of recession and unemployment when it maintains the currency board.

Given those parameters, the optimal commitment for the H-type is 0 if there is no asymmetric information (Figure 10a). If the market misinterprets the government as an L-type, the optimal response for an H-type government depends on the market perception of $X_{L}$. For $X_{L}$ small enough, there is a separating equilibrium. In particular, if $X_{L}$ is smaller than $X_{\text {sep }}^{p^{*}}$, an H-type would simply commit a bit more than $C_{L}^{\text {Indiff }}$ to induce a separating equilibrium. For $X_{L}$ larger than $X_{s e p}^{p^{*}}$, the H-type can still separate itself from L-type by committing $C_{L}^{\text {Indiff }}$, but it is not in the interest of H-type to do so. Thus, the H-type will simply commit $C_{L}^{p^{*}}$ (to take the Ltype's commitment that will avert a collapse of the currency board at $t=0$ ) and pool itself with the L-type. But this is a good pooling equilibrium, as the currency board will not collapse.

The situation portrayed in figure 10a resembles that of the Hong Kong experience in the summer of 1998. After the Russian default, there was an exodus of capital from Hong Kong as the market was unsure of the determination of the Hong Kong Monetary Authority to maintain the currency board. In September, the Hong Kong Monetary Authority announced a reserve commitment backing its currency board and the exodus stopped.

\section{Figure 10a about here}

Figure $10 \mathrm{~b}$ is essentially the same as figure 10a, except that the H-type has lower determination $\left(X_{H}=1\right.$ rather than 3 ). In this case, the optimal commitment for $X_{H}$, in the absence of asymmetric information, is about 5. But if there is asymmetric information, the H-type may have to commit more to induce a separating equilibrium or a good pooling equilibrium (similar to the case in figure 10a).

\section{Figure 10b about here}

\footnotetext{
${ }^{26}$ Data is available from the Monthly Statistical Bulletin or web site (http://www.info.gov.hk/hkma/index.htm) of the Hong Kong Monetary Authority.
} 
Figure 10c illustrates the case when the penalty of losing foreign currency reserves is small (small $g$ ). In this case, the L-type has a stronger incentive to mimic the H-type. Since the distinction between H-type and L-type is difficult, most of the time there will be a pooling equilibrium. There are still good and bad pooling equilibriums. If $X_{L}$ is close enough to $X_{H}$, both H-type and L-type can commit $C_{L}^{p^{*}}$ to generate a good pooling equilibrium so that there would not be any runs against the currency board. On the other hand, if the public perceives the H-type with a low $X_{L}$, the currency board will collapse in a bad pooling equilibrium with currency board runs. The left most part of the graph shows that if the public perceives $H$ to have an extremely low $X_{L}$, it is possible for the H-type to separate itself from the L-type with large enough commitment. This would not be a robust separating equilibrium as a higher $X_{L}$ would induce the currency board to collapse. Thus, in the case where $g$ (the penalty for losing reserves) is small and therefore it is difficult for the H-type to separate itself from the L-type, the most likely outcome would be a pooling equilibrium, both good and bad.

\section{Figure 10c about here}

\subsubsection{The Argentina examples}

At the end of November 2001, Argentina had about $\$ 16$ billion in liquid reserves and an M3 in peso of about $\$ 32$ billion $^{27}$. Thus, we set $M=20$ and $R=10$. Based on these numbers, the reserves to $\mathrm{M} 3$ ratio (assuming that the reserves were unencumbered by off-balance sheet obligations 5 for Argentina was actually more favorable than that of Hong Kong. We keep all other parameters for Argentina the same as those in figure 10a, including the government's

\footnotetext{
${ }^{27}$ Data is available from the Daily Monetary Report of the Central Bank of Argentina from the web site (http://www.bcra.gov.ar/English/default.asp).

${ }^{28}$ In the simulations below, we assume that there is a separation between the national bank (currency board) and the government in the sense that the national bank does not have the additional obligations to pay government debts and bail out the banking system if the banks mismanage their currency risks. Such separation is essential to the credibility of hard-fixed exchange rate systems (e.g., the European monetary union). If the reserves are encumbered to pay government debts, our model is flexible enough to accommodate that by either reducing $R$ by the encumbered amount or increasing $\alpha$, whichever is more appropriate to the actual scenario. Furthermore, there could be some externalities arising from the weight of government debts to the credibility of a fixed exchange rate. When Argentina suspended debt payment on December 24, 2001, even though it simultaneously pledged to keep its currency board (Reuters), the damaged credibility finally forced Argentina to abandon its currency board in January. In our model, we would assign a higher $X$ before the debt moratorium than after the debt moratorium. We would assign a lower " $a$ " for the Argentine currency board if the government had a smaller amount of debt or a greater credible debt capacity. At the end of 2001, the debt to GDP(2000) ratio for Argentina was 44 percent, which was actually lower than that of each of the G7 country (Britain 47 percent, US 57 percent, Germany 58 percent, France 63 percent, Canada 106 percent, Japan 109 percent and Italy 110 percent. Source: Economists)
} 
determination $X_{H}=3$, perceived renege cost relative to M3), except $\alpha$ and $a$. For Argentina, we set $\alpha=0.1$ (the capital outflow parameter, compared with $\alpha=0.05$ for Hong Kong) because the Argentine economy was mired in a four-year old recession at the end of 2001 with disillusioned investors investing their money elsewhere, as compared to the Hong Kong's economy which continued to be a beneficiary of the robust Chinese economy during the East Asian financial crisis. We set $a=1$ for Argentina (compared with $a=0.5$ for Hong Kong) as Argentina has a much more rigid economy and labor market, and a large public debt. After the devaluation of the Mexican peso and the Brazilian real, the domestic price structure adjustment was slow and painful and Argentina went into a deepening recession with unemployment rate reaching more than 18 percent. The government was caught between the IMF that required them to exercise fiscal disciplines and the Argentines who wanted more government spending to bail the country out of a recession, which ultimately cumulated in widespread protests and deadly riots.

Figure 11a-c plot several scenarios corresponding to different parameters $\left(a, X_{H}\right)$ with the values of $X_{L}$ on the X-axis. In figure $11 \mathrm{a}$, the commitment $C$ has to be more than 12 to avert runs but the government has only $R=10$ in reserves. Thus, the collapse of the currency board is unavoidable and there would be runs against the currency board (via the banking system as in Argentina in December 2001).

\section{Figure 11a about here}

Could the outcomes be different under some other parameter values? Figure $11 \mathrm{~b}$ and $11 \mathrm{c}$ illustrate two possible scenarios with positive outcomes. In figure $11 \mathrm{~b}$, we assume that $X_{H}$ is 4 (rather than 3 in figure 11a). At this higher level of determination, it is possible to avert runs against its currency board if the government is willing to guarantee the currency board with an irrevocable commitment (i.e., with no default possibility, see footnote 15). To translate this to the Argentine scenario, the government would have to (i) stop tinkering with the hard-fixed exchange rate of its currency board with exit strategies (as it did in June 2000), (ii) convince the market that its perceived renege cost is very high and it is willing to withstand even deadly riots to continue its currency board and service its international debts [as Argentina was actually doing

\footnotetext{
${ }^{29}$ It took deadly riots and five presidents in two weeks to finally bring down the currency board in Argentina. It would seem reasonable to assume that the determinations of Hong Kong and Argentina were both high in preserving the currency board.
} 
even in the week of December 17 (Reuters, December 20, 2001) before the president resigned] and, to further convince the market, (ii) makes an irrevocable commitment of $C_{H}^{p^{*}}$ (which, according to figure $11 \mathrm{~b}$, is almost the entire reserves) to guarantee the currency board.

\section{Figure 11b about here}

Alternatively, in figure 11c, we keep $X_{H}=3$ but lower $a$ to 0.5 (the same as Hong Kong). In this case, the government can easily avert runs with a small irrevocable commitment. Thus, if the Argentine politicians could convince the people to readily accept a flexible wage and price structure in response to the currency devaluations of its competing economies or the IMF for emergency loans to cover its relief fiscal spending, the adjustment pain ("social loss") to the government for sticking to the currency board is low. When this is combined with an irrevocable commitment to signal its resolves, the currency board would have survived.

\section{Figure 11c about here}

\subsubsection{Calibration and policy tools}

The simulations in figures $10 \mathrm{abc}$ and $11 \mathrm{abc}$ illustrate how the parameters in our currency board model, in particular the role of an irrevocable reserves commitment, interact to determine the viability of a currency board. It is easy to infer from these simulations about the importance of economic flexibility and reserve commitments to the survival of a hard-fixed exchange rate system. Although the results are derived with many simplifying assumptions, the main implications are likely to be robust to minor modifications to the model, such as changing the statistical distribution of the shock or replacing the loss function with another smooth monotonic function. The ranges of the different equilibriums might be dependent on the specific functions, but the main economic scenarios will remain the same.

\footnotetext{
${ }^{30}$ The parameter " $a$ " would be lower if multilateral organizations like the IMF can be relied upon to provide emergency relief for extra fiscal spending to ease the adjustment pains. This is similar in spirit to a provision in the European monetary union that allows member countries affected by negative shocks to violate fiscal restrictions without penalties. The IMF is particularly well suited for providing this type of emergence loans to carry a country over an economic shock. Indeed, in December 2000, the IMF (and the US Treasury), in taking the leadership in putting together a package of $\$ 20$ billion emergency loans to Argentina, believed that the package "should improve the investment climate and, together with enhanced domestic and external confidence, lay the ground for sustained economic growth in Argentina (Financial Times, December 19, 2000).” In August 2001, the IMF offered another $\$ 8$ billion in aids. But, in December 2001, the IMF finally got impatient with Argentina's fiscal deficits (perpetuated by local politics) and withheld the anticipated aid. The action weakened the already fragile confidence in Argentina and eventually led to a full-blown crisis.
} 
The simulations highlight the impact of the changes in parameter value on the model implications. The differences in the simulation input values are not intended to be taken literally, but rather as an illustration of how they can influence the outcomes. To turn the model into a policy tool, one would substitute into the model the appropriate parameters corresponding to the problem at hand. In this sense, our model can be viewed as a general framework upon which government policy makers can put in their own favorite social loss functions and their estimated shock distribution function to simulate the relevant scenarios. From the results of those sensitivity analyses, they can then design the appropriate policy remedies if necessary.

\section{Conclusion}

This paper provides a simple theoretical framework for analyzing a currency board system. Within this framework, we investigate the role of an irrevocable commitment for enhancing the stability of a currency board. Our results highlight the important functions of foreign currency reserves in a currency board system. In the traditional thinking of a currency board arrangement, foreign currency reserves are considered only as a shock absorber for the changes in the demand of domestic currency. In this paper, we show that the foreign reserve can be used, perhaps more importantly, as a costly signal in the form of an irrevocable commitment. Through the reserve commitment policy, the foreign currency reserves can provide two additional functions. First, it can reduce the probability of "bad" equilibriums (runs against the currency board). Second, with information asymmetry, a government with strong resolve can signal its true type to the public by extra reserve commitment. Both of these functions can further enhance the stability of a currency board system.

We illustrate the implications of our model by calibrating it with the financial crisis environments facing Argentina in 2001-02 and Hong Kong in 1997-98. In the Argentina case, we show that the runs against its currency board would be unavoidable given certain parameter values reflecting the rigidity of its economy and labor market in response to currency devaluations of its competing economies. Our model also suggests that a combination of policy remedies together with an irrevocable reserves commitment backing the currency board could possibly have saved the Argentine currency board from its collapse and the Argentine economy from its ensuring turmoil. 
Perhaps more importantly, if Argentina (or any other country) wants to enter into a fixed exchange rate arrangement again in the future to win back the confidence of international investors and the credibility of its monetary and fiscal policies to the people, the relevant economic environment can be analyzed with our framework to assess how an irrevocable commitment can be combined with other policy remedies to stabilize the fixed exchange rate arrangement. Although our analysis is based on a currency board arrangement, which is just one variation of a variety of "hard-fixed" exchange rate arrangements, our model can be easily adapted to analyze financial crises arising in other variations (see footnote 4), such as dollarizations or monetary unions, and suggest possible remedies if necessary.

The Hong Kong currency board was also under tremendous pressure during the 1997-98 Asian financial crisis. After Russia defaulted in the summer of 1998 and the Hong Kong government intervened massively in the stock market in August 1998, the market sentiment was extremely fragile. People were unsure of the government's resolves to preserve the currency board. In the morning of September 14, 1998, the banks in Hong Kong were selling Hong Kong dollars aggressively to the Hong Kong Monetary Authority (HKMA, the currency board) upon the rumor that the prevailing exchange rate for the "Convertibility Undertaking Arrangement" would be adjusted imminently. At 2:00pm, in desperation, the HKMA announced that the conversion of government bills via the banking system's discount window and the currency board into U.S. dollars would be honored at the prevailing exchange rate for the next six months. The announcement effectively adopted the CCM recommendation by attaching a six-month domestic currency put option onto the outstanding bills, representing a reserve commitment of about US\$8 billions backing the currency board.

The empirical support for the benefit of commitment was immediate and compelling. Within the next three days, all the capital that flowed out of Hong Kong in the morning of September 14, 1998 flowed back to Hong Kong plus a little more [see Morgan Stanley (1998)]. The Hong Kong market did not even shake in the following week when the near collapse of LTCM roiled the world financial markets. In the end, the Hong Kong economy emerged mostly unscathed after some adjustment pains and the Hong Kong dollar was one of the few freely traded hard currencies in the world that did not depreciate against the U.S. dollar during the crisis period of 1997-98. 
Appendix: Mathematical Proofs

\section{A.1 Proof of Proposition (I)}

We can solve $z^{*}$ such that the government is indifferent to link or delink when $S=z^{*}$.

$$
\begin{aligned}
& L^{L}\left|z^{*}=L^{D}\right| z^{*} \\
& a \times z^{*}=X+\left(f_{L}-f_{D}\right) \\
& z^{*}=\left[\frac{X+\left(f_{L}-f_{D}\right)}{a}\right]
\end{aligned}
$$

Since the government has foreign reserve holdings, $R$, to absorb the external money domestic shock, the value of $z^{*}$ must be in-between $[0, R]$. If $z^{*} \geq R$ then $z^{*}=R$. It means that the government will never voluntarily delink. It is straightforward to derive the upper critical value $(\bar{X})$ for the government's determination in maintaining the currency board, $(X)$.

- End of Proof -

\section{A.2 Proof of Proposition (II)}

Under a foreign reserve commitment policy $(C)$, we can solve $z_{C}^{*}$ such that the government is indifferent to link or delink when $S=z_{C}^{*}$.

$$
\begin{aligned}
& L^{L}\left|z_{C}^{*}=L^{D}\right| z_{C}^{*} \\
& a \times z_{C}^{*}=X+\left(f_{L}-f_{D}\right)+g \times C \\
& z_{C}^{*}=\frac{X+\left(f_{L}-f_{D}\right)+g \times C}{a}
\end{aligned}
$$

The available foreign reserve $(R)$ imposes an upper limit on the government's ability to absorb the external shock. If $z_{C}^{*} \geq R$, then $z_{C}^{*}=R$. It means that the government will never voluntarily delink. It is easy to see that $z_{C}^{*}$ reaches $R$ when $X \geq\left[(a \times R-g \times C)-\left(f_{L}-f_{D}\right)\right]$, which is defined to be $\bar{X}_{C}$.

Note: $z_{C}^{*}$ can be less than the committed reserve $(C)$. 


\section{A.3 Proof that $G\left(X, p^{*}\right)$ is an increasing function with $X$ (for $X<X_{\text {Safe }}^{p^{*}}$ )}

For a government with $X$, which is less than $X_{\text {Safe }}^{p^{*}}$, let $p$ be the probability of delink. If a government chooses not to commit any reserve, there will be a public's panic run (because $X<$ $\left.X_{\text {Safe }}^{p^{*}}\right)$. Hence,

$$
\begin{aligned}
& E\left[L \mid C=0, p>p^{*}\right] \\
& =E[L \mid C=0, \text { with Public's Panic Run }] \\
& =L^{D} \\
& =\left[X+\left(f_{L}-f_{D}\right)\right]
\end{aligned}
$$

If a government chooses to commit $C^{p^{*}}(X), p=p^{*}$ and there will be no panic run. Hence,

$$
\begin{aligned}
& E\left[L \mid C=C^{p^{*}}, \text { No Public's Panic Run }\right] \\
& =p \times E\left[L \mid C=C^{p^{*}}, \text { No Public's Panic Run, }\left(z_{C}^{p^{*}}<S\right)\right] \\
& \quad+(1-p) \times E\left[L \mid C=C^{p^{*}}, \text { No Public's Panic Run, }\left(-M \leq S \leq z_{C}^{p^{*}}\right)\right] \\
& =p \times L_{C^{*}}^{D}+(1-p) \times E\left[L_{C^{*}}^{L}\right] \\
& =\left[p^{*} \times L_{C^{*}}^{D}+\left(1-p^{*}\right) \times E\left[L_{C^{*}}^{L}\right]\right]
\end{aligned}
$$

where $p=$ Probability of Delink $=\left[\frac{(\alpha+\beta) \times M-z_{C}^{*}}{2 \beta M}\right]$. Using $C=C^{p^{*}}$, we have $p=p^{*}$

$$
\text { and } z_{C}^{*}=z_{C}^{p^{*}}
$$$$
L_{C^{*}}^{D}=\text { Social Loss from Delink, }
$$$$
\text { given that (i) } C=C^{p^{*}} \text { and (ii) No Public's Panic Run }
$$$$
=\left[L \mid C=C^{p^{*}}, \text { No Public's Panic Run, }\left(z_{C}^{p^{*}}<S\right)\right]
$$$$
=\left[X+\left(f_{L}-f_{D}\right)+g \times C^{p^{*}}\right]
$$

$E\left[L_{C^{*}}^{L}\right]=$ Expected Social Loss from Maintaining the Link,

$$
\begin{aligned}
& \text { given that (i) } C=C^{p^{*}}, \text { and (ii) No Public's Panic Run } \\
= & E\left[L \mid C=C^{p^{*}}, \text { No Public's Panic Run, }\left((\alpha-\beta) \times M \leq S \leq z_{C}^{p^{*}}\right)\right] \\
= & {\left[\left(\frac{a}{2 \times\left[z_{C}^{p^{*}}-(\alpha-\beta) \times M\right]}\right) \times\left(z_{C}^{p^{*}}\right)^{2}\right] }
\end{aligned}
$$


Note: We assume the social loss from maintaining the link is zero if the external shock is a capital inflow.

The gain from using reserve commitment $C^{p^{*}}(X)$ to avoid the public's panic run for government-type $X$ is ${ }^{31}$ :

Gain from using $\left(C^{p^{*}}\right)$

$=G\left(X, p^{*}\right)$

$=E[L \mid C=0$, with Public's Panic Run $]-E\left[L \mid C=C^{p^{*}}\right.$, No Public's Panic Run $]$

$=\left[X+\left(f_{L}-f_{D}\right)\right]-\left[p^{*} \times L_{C^{*}}^{D}+\left(1-p^{*}\right) \times E\left[L_{C^{*}}^{L}\right]\right]$

$=\left[X+\left(f_{L}-f_{D}\right)\right]$

$-\left\{p^{*} \times\left[X+\left(f_{L}-f_{D}\right)+g \times C^{p^{*}}\right]+\left(1-p^{*}\right) \times\left[\left(\frac{a}{2 \times\left[z_{C}^{p^{*}}-(\alpha-\beta) \times M\right]}\right) \times\left(z_{C}^{p^{*}}\right)^{2}\right]\right\}$

A government will commit $C^{p^{*}}$ if and only if $G\left(X, p^{*}\right) \geq 0$.

Firstly, it is obvious that $\left(\frac{\partial E[L \mid C=0 \text {, with Public's Panic Run }]}{\partial X}\right)=1$. Secondly, as

$C^{p^{*}}=\left\{\frac{a M \times\left[\beta \times\left(1-2 p^{*}\right)+\alpha\right]-X-\left(f_{L}-f_{D}\right)}{g}\right\}$, we have $\frac{\partial C^{p^{*}}}{\partial X}=\frac{-1}{g}$,

$z_{C}^{p^{*}}=\left(\frac{X+\left(f_{L}-f_{D}\right)+g \times C^{p^{*}}}{a}\right)$, and $\frac{\partial z_{C}^{p^{*}}}{\partial X}=\left(\frac{1}{a}+\frac{g}{a} \times \frac{\partial C^{p^{*}}}{\partial X}\right)=\left(\frac{1}{a}+\frac{g}{a} \times \frac{-1}{g}\right)=0$. Hence,

$\frac{\partial L_{C^{*}}^{D}}{\partial X}=\left(1+g \times \frac{\partial C^{p^{*}}}{\partial X}\right)=\left(1+g \times \frac{-1}{g}\right)=0$ and $\frac{\partial E\left[L_{C^{*}}^{L}\right]}{\partial X}=0$. And then, we have

$\left(\frac{\partial E\left[L \mid C^{p^{*}}, \text { No Public's Panic Run }\right]}{\partial X}\right)=\left(p^{*} \times \frac{\partial L_{C^{*}}^{D}}{\partial X}+\left(1-p^{*}\right) \times \frac{\partial E\left[L_{C^{*}}^{L}\right]}{\partial X}\right)=0$.

Hence, for $X_{R u n}^{p^{*}} \leq X<X_{\text {Safe }}^{p^{*}}$ and any $C^{p^{*}} \in[0, R]$, we have

$$
\begin{aligned}
\frac{\partial G}{\partial X} & =\left[\left(\frac{\partial E[L \mid C=0, \text { with Public's Panic Run }]}{\partial X}\right)-\left(\frac{\partial E\left[L \mid C^{p^{*}}, \text { No Public's Panic Run }\right]}{\partial X}\right)\right] \\
& >0
\end{aligned}
$$

31 As all social losses are denominated in the foreign currency and interest rate for foreign currency is assumed to be zero, there is no time value effect on the future value of social loss. 
The gain from using reserve commitment $C^{p^{*}}, G\left(X, p^{*}\right)$, under perfect information is an increasing function with $X$.

\section{- End of Proof -}

\section{A.4 Proof of Proposition (III)}

We want to show that if a solution $X^{\#}$ exists, that it is unique. To consider only the relevant cases, we assume (i) $X_{L}<X_{H}$, (ii) $X_{L}<\min \left\{X_{\text {Safe }}^{p^{*}},\left[a \times R-\left(f_{L}-f_{D}\right)\right]\right\}$, and (iii) $\max \left\{X_{\text {Run }}^{p^{*}}, X_{\text {Indiff }}^{p^{*}}\right\}<X_{H}$. Within this parameter range, we want to show that the gain of a government of L-type from imitating the H-type (by committing $C_{H}^{p^{*}}$ ) is increasing with the value $X_{L}$. If so, $X^{\#}$ is unique if a solution exists for $0<X^{\#}<X_{H}$. Among other things, this would imply that all governments with sufficiently low $X_{L}$ would choose not to commit any reserve (to avert the public's run against the currency board).

Let $z_{C_{H}^{p^{*}}}^{L}$ denote the maximum amount of shock a government (with $X_{L}$ and reserve commitment $C_{H}^{p^{*}}$ ) is willing to and able to absorb without delinking.

Under perfect information, if a government with $X_{H}$ commits more than $\left(\frac{a \times R-\left[X_{H}+\left(f_{L}-f_{D}\right)\right]}{g}\right)$, it will only incur more cost but cannot further increase its $z_{C}^{*}$ as $z_{C}^{*}=R$. Hence, the reserve commitment level, $C_{H}^{p^{*}}$, for $X_{H}$ to avoid panic run under perfect information situation must be equal to or less than $\left(\frac{a \times R-\left[X_{H}+\left(f_{L}-f_{D}\right)\right]}{g}\right)$, i.e. $C_{H}^{p^{*}} \leq\left(\frac{a \times R-\left[X_{H}+\left(f_{L}-f_{D}\right)\right]}{g}\right)$

By the definition, $z_{C_{H}^{p^{*}}}^{L}=\min \left\{\left(\frac{X_{L}+\left(f_{L}-f_{D}\right)+g \times C_{H}^{p^{*}}}{a}\right), R\right\}$, and $\left(\frac{X_{L}+\left(f_{L}-f_{D}\right)+g \times C_{H}^{p^{*}}}{a}\right)$ 
$\leq\left(\frac{a \times R-\left(X_{H}-X_{L}\right)}{a}\right)$

$<R$ because

because

$$
C_{H}^{p^{*}} \leq\left(\frac{a \times R-\left[X_{H}+\left(f_{L}-f_{D}\right)\right]}{g}\right)
$$

$$
X_{L}<X_{H}
$$

thus $z_{C_{H}^{p^{*}}}^{L}=\left(\frac{X_{L}+\left(f_{L}-f_{D}\right)+g \times C_{H}^{p^{*}}}{a}\right)$.

Let $p_{C_{H}^{p^{*}}}^{L}$ denote the probability of delink if a government with determination $X_{L}$ commits foreign reserve $C_{H}^{p^{*}}$ (to mimic $X_{H}$ ), and there is no public's panic run. Hence, $p_{C_{H}^{p^{*}}}^{L}$

$=\operatorname{Prob}\left\{\right.$ Delink $\mid X=X_{L}, C=C_{H}^{p^{*}}$, No Public's Panic Run $\}$

$=\operatorname{Prob}\left\{S>z_{C_{H}^{p^{*}}}^{L} \mid X=X_{L}, C=C_{H}^{p^{*}}\right.$, No Public's Panic Run $\}$

As $z_{C_{H}^{p^{*}}}^{L}=\left(\frac{X_{L}+\left(f_{L}-f_{D}\right)+g \times C_{H}^{p^{*}}}{a}\right)$, we have

$p_{C_{H}^{p^{*}}}^{L}=\left[\frac{(\alpha+\beta) \times M-z_{C_{H}^{p^{*}}}^{L}}{2 \beta M}\right]=(2 \beta M)^{-1} \times\left[(\alpha+\beta) M-\left(\frac{X_{L}+\left(f_{L}-f_{D}\right)+g \times C_{H}^{p^{*}}}{a}\right)\right]$.

\section{Social Loss of a Government with $X_{L}$ with No Reserve Commitment}

Since $X_{L}<X_{\text {Safe }}^{p^{*}}$ and the public believes that a government with $X_{H}$ commits $C_{H}^{p^{*}}$, there must be a public's panic run if a government with $X_{L}$ does not commit any reserve.

$E\left[L \mid X=X_{L}, C=0\right.$, with Public's Panic Run $]$

$=L^{D}$

$=\left[X_{L}+\left(f_{L}-f_{D}\right)\right]$

\section{Social Loss of a Government with $X_{L}$ Committing $C_{H}^{p^{*}}$}

$E\left[L \mid X=X_{L}, C=C_{H}^{p^{*}}\right.$, No Public's Panic Run $]$

$=p_{C_{H}^{p^{*}}}^{L} \times E\left[L \mid X=X_{L}, C=C_{H}^{p^{*}}\right.$, No Public's Panic Run, $\left.\left(z_{C_{H}^{p^{*}}}^{L}<S\right)\right]$

$+\left(1-p_{C_{H}^{p^{*}}}^{L}\right) \times E\left[L \mid X=X_{L}, C=C_{H}^{p^{*}}\right.$, No Public's Panic Run, $\left.\left((\alpha-\beta) M \leq S \leq z_{C_{H}^{p^{*}}}^{L}\right)\right]$

$=\left[p_{C_{H}^{p^{*}}}^{L} \times L_{C_{H}^{p^{*}, X_{L}}}^{D}+\left(1-p_{C_{H}^{p^{*}}}^{L}\right) \times E\left[L_{C_{H}^{p^{*}}, X_{L}}^{L}\right]\right]$

where 
$p_{C_{H}^{p^{*}}}^{L}=$ Probability of Delink,

given that (i) $X=X_{L}$, (ii) $C=C_{H}^{p^{*}}$, and (iii) No Public's Panic Run

$=\left[\frac{(\alpha+\beta) \times M-z_{C_{H}^{p^{*}}}^{L}}{2 \beta M}\right]$

$L_{C_{H}^{p^{*}, X_{L}}}^{D}=$ Social Loss from Delink,

given that (i) $X=X_{L}$, (ii) $C=C_{H}^{p^{*}}$, and (iii) No Public's Panic Run

$=\left[L \mid X=X_{L}, C=C_{H}^{p^{*}}\right.$, No Public's Panic Run, $\left.\left(z_{C_{H}^{p^{*}}}^{L}<S\right)\right]$

$=\left[X_{L}+\left(f_{L}-f_{D}\right)+g \times C_{H}^{p^{*}}\right]$

$E\left[L_{C_{H}^{p^{*}}, X_{L}}^{L}\right]=$ Expected Social Loss from Maintaining the Link, given that (i) $X=X_{L}$, (ii) $C=C_{H}^{p^{*}}$, and (iii) No Public's Panic Run

$=E\left[L \mid X=X_{L}, C=C_{H}^{p^{*}}\right.$, No Public's Panic Run, $\left.\left((\alpha-\beta) M \leq S \leq z_{C_{H}^{p^{*}}}^{L}\right)\right]$

$=\left[\left(\frac{a}{2 \times\left[z_{C_{H}^{p^{*}}}^{L}-(\alpha-\beta) \times M\right]}\right) \times\left(z_{C_{H}^{p^{*}}}^{L}\right)^{2}\right]$

Note: We assume the social loss from maintaining the link is zero if the external contraction shock on money demand is negative.

It is easily to show that

$$
\begin{aligned}
\frac{\partial C_{H}^{p^{*}}}{\partial X_{L}}=0, & \frac{\partial z_{C_{H}^{p^{*}}}^{L}}{\partial X_{L}}=\left(\frac{1}{a}\right), \quad \frac{\partial p_{C_{H}^{p^{*}}}^{L}}{\partial X_{L}}=\left(\frac{-1}{2 a \beta M}\right), \quad \frac{\partial L_{C_{H}^{p^{*}}, X_{L}}^{D}}{\partial X_{L}}=1, \\
\frac{\partial E\left[L_{C_{H}^{p^{*}, X_{L}}}^{L}\right]}{\partial X_{L}} & =\left(\frac{-a}{2 \times\left[z_{C_{H}^{p^{*}}}^{L}-(\alpha-\beta) \times M\right]^{2}}\right) \times \frac{\partial z_{C_{H}^{p^{*}}}^{L}}{\partial X_{L}} \times\left(z_{C_{H}^{p^{*}}}^{L}\right)^{2}+\left(\frac{a}{2 \times\left[z_{C_{H}^{p^{*}}}^{L}-(\alpha-\beta) \times M\right]}\right) \times 2 \times z_{C_{H}^{p^{*}}}^{L} \times \frac{\partial z_{C_{H}^{p^{*}}}^{L}}{\partial X_{L}} \\
& =\left(\frac{z_{C_{H}^{p^{*}}}^{L}}{\left[z_{C_{H}^{p^{*}}}^{L}-(\alpha-\beta) \times M\right]}\right) \times\left(1-\frac{1}{2} \times\left(\frac{z_{C_{H}^{p^{*}}}^{L}}{\left[z_{C_{H}^{p^{*}}}^{L}-(\alpha-\beta) \times M\right]}\right)\right.
\end{aligned}
$$

Hence, 


$$
\begin{aligned}
& \frac{\partial E\left[L \mid X=X_{L}, C=C_{H}^{p^{*}}, \text { No Public's Panic Run }\right]}{\partial X_{L}} \\
& =\left[\frac{\partial p_{C_{H}^{p^{*}}}^{L}}{\partial X_{L}} \times L_{C_{H}^{p^{*}, X_{L}}}^{D}+p_{C_{H}^{p^{*}}}^{L} \times \frac{\partial L_{C_{H}^{p^{*}, X_{L}}}^{D}}{\partial X_{L}}+\frac{\partial\left(1-p_{C_{H}^{p^{*}}}^{L}\right)}{\partial X_{L}} \times E\left[L_{C_{H}^{p^{*}}, X_{L}}^{L}\right]+\left(1-p_{C_{H}^{p^{*}}}^{L}\right) \times \frac{\partial E\left[L_{C_{H}^{p^{*}}, X_{L}}^{L}\right]}{\partial X_{L}}\right] \\
& =\left[\frac{(\alpha+\beta) \times M-z_{C_{H}^{p^{*}}}^{L}}{2 \beta M}\right]
\end{aligned}
$$

Now, let's examine the gain of a government with $X_{L}$ from imitating a government with $X_{H}$.

Gain for $X_{L}$ to Imitate $X_{H}$ from Committing $C_{H}^{p^{*}}$

$=G I\left(X_{L}, X_{H}\right)$

$=E\left[L \mid X=X_{L}, C=0\right.$, with Public's Panic Run $]-E\left[L \mid X=X_{L}, C=C_{H}^{p^{*}}\right.$, No Public's Panic Run $]$

$=\left[X_{L}+\left(f_{L}-f_{D}\right)\right]-\left[p_{C_{H}^{p^{*}}}^{L} \times L_{C_{H}^{p^{*}}, X_{L}}^{D}+\left(1-p_{C_{H}^{p^{*}}}^{L}\right) \times E\left[L_{C_{H}^{p^{*}}, X_{L}}^{L}\right]\right]$

It is obvious that

$$
\begin{aligned}
& \frac{\partial G I\left(X_{L}, X_{H}\right)}{\partial X_{L}} \\
& =\left\{\frac{\partial E\left[L \mid X=X_{L}, C=0, \text { with Public's Panic Run }\right]}{\partial X_{L}}-\frac{\partial E\left[L \mid X=X_{L}, C=C_{H}^{p^{*}}, \text { No Public's Panic Run }\right]}{\partial X_{L}}\right\} \\
& =\left[\frac{z_{C_{H}^{p^{*}}}^{L}-(\alpha-\beta) \times M}{2 \beta M}\right] \\
& >0
\end{aligned}
$$$$
\text { because } \quad \alpha \leq \beta \text { and } 0 \leq z_{C_{H}^{p^{*}}}^{L} \leq R<M
$$

- End of Proof -

\section{A.5 Proof of the uniqueness of $C_{L}^{\text {Indiff }}$ and $C_{H}^{\text {Indiff }}$}

It is sufficient to show that conditional on no public panic run, the gain $G(X, C)$ is decreasing with $C$.

$$
G(X, C)=\left[X+\left(f_{L}-f_{D}\right)\right]-\left\{\begin{array}{l}
p \times\left[X+\left(f_{L}-f_{D}\right)+g \times C\right] \\
+(1-p) \times\left[\left(\frac{a}{2 \times\left[z_{C}^{*}-(\alpha-\beta) \times M\right]}\right) \times\left(z_{C}^{*}\right)^{2}\right]
\end{array}\right\}
$$


Case 1: $\quad z_{C}^{*}=\left(\frac{X+\left(f_{L}-f_{D}\right)+g \times C}{a}\right)<R$

$C=\left(\frac{a \times z_{C}^{*}-\left(X+\left(f_{L}-f_{D}\right)\right)}{g}\right), p=\left[\frac{(\alpha+\beta) \times M-z_{C}^{*}}{2 \beta M}\right]$ and $1-p=\left[\frac{z_{C}^{*}-(\alpha-\beta) \times M}{2 \beta M}\right]$

$G(X, C)$

$=\left[X+\left(f_{L}-f_{D}\right)\right]-\left[\frac{a \times(\alpha+\beta)}{2 \beta}\right] \times z_{C}^{*}+\left(\frac{a}{4 \beta M}\right) \times\left(z_{C}^{*}\right)^{2}$

$\frac{\partial G}{\partial C}=\frac{\partial G}{\partial z_{C}^{*}} \times \frac{\partial z_{C}^{*}}{\partial C}$

$=\frac{g}{2 \beta} \times\left[\frac{z_{C}^{*}}{M}-(\alpha+\beta)\right]$

$<0$

because $0 \leq z_{C}^{*} \leq R<(\alpha+\beta) \times M$.

Case 2: $\quad z_{C}^{*}=R$

$p=\left[\frac{(\alpha+\beta) \times M-R}{2 \beta M}\right]$ and $1-p=\left[\frac{R-(\alpha-\beta) \times M}{2 \beta M}\right]$

$G(X, C)$

$=\left[X+\left(f_{L}-f_{D}\right)\right]-\left\{\begin{array}{l}{\left[\frac{(\alpha+\beta) \times M-R}{2 \beta M}\right] \times\left[X+\left(f_{L}-f_{D}\right)+g \times C\right]} \\ +\left[\frac{R-(\alpha-\beta) \times M}{2 \beta M}\right] \times\left[\left(\frac{a}{2 \times[R-(\alpha-\beta) \times M]}\right) \times R^{2}\right]\end{array}\right\}$

$\frac{\partial G}{\partial C}=-\left[\frac{(\alpha+\beta) \times M-R}{2 \beta M}\right] \times g<0 \quad$ because $\quad 0<R<(\alpha+\beta) \times M$.

Hence, $\frac{\partial G}{\partial C}<0$ for all $X$, given that $0<R<(\alpha+\beta) \times M$. Therefore, the solutions to $(17$ and $(18$ are unique within the meaningful range.

- End of Proof - 


\section{A.6 Proof that $C_{L}^{\text {Indiff }}<C_{H}^{\text {Indiff }}$}

To prove $C_{L}^{\text {Indiff }}<C_{H}^{\text {Indiff }}$, let's first prove the fact that $G(X, C)$ is an increasing function with $X$ for any given $C$.

$$
G(X, C)=\left[X+\left(f_{L}-f_{D}\right)\right]-\left\{\begin{array}{l}
p \times\left[X+\left(f_{L}-f_{D}\right)+g \times C\right] \\
\left.+(1-p) \times\left[\left(\frac{a}{2 \times\left[z_{C}^{*}-(\alpha-\beta) \times M\right]}\right) \times\left(z_{C}^{*}\right)^{2}\right]\right\}
\end{array}\right.
$$

Case 1: $\quad z_{C}^{*}=\left(\frac{X+\left(f_{L}-f_{D}\right)+g \times C}{a}\right)<R$

$$
\begin{aligned}
& p=\left[\frac{(\alpha+\beta) \times M-z_{C}^{*}}{2 \beta M}\right] \quad \text { and } \quad 1-p=\left[\frac{z_{C}^{*}-(\alpha-\beta) \times M}{2 \beta M}\right] \\
& \frac{\partial z_{C}^{*}}{\partial X}=\frac{1}{a}, \quad \frac{\partial p}{\partial X}=\frac{\partial p}{\partial z_{C}^{*}} \times \frac{\partial z_{C}^{*}}{\partial X}=\frac{-1}{2 \beta M} \times \frac{1}{a}=\left(\frac{-1}{2 a \beta M}\right)
\end{aligned}
$$

Let $\Delta=\left[\left(\frac{a}{2 \times\left[z_{C}^{*}-(\alpha-\beta) \times M\right]}\right) \times\left(z_{C}^{*}\right)^{2}\right]$

$$
\begin{aligned}
\frac{\partial \Delta}{\partial z_{C}^{*}} & =\frac{a}{2} \times\left[-1 \times\left[z_{C}^{*}-(\alpha-\beta) \times M\right]^{-2} \times\left(z_{C}^{*}\right)^{2}+2 \times\left[z_{C}^{*}-(\alpha-\beta) \times M\right]^{-1} \times z_{C}^{*}\right] \\
& =\frac{a}{2 \times\left[z_{C}^{*}-(\alpha-\beta) \times M\right]^{2}} \times\left[\left[z_{C}^{*}\right)^{2}-2 \times(\alpha-\beta) \times M \times z_{C}^{*}\right]
\end{aligned}
$$

$$
\begin{aligned}
\frac{\partial \Delta}{\partial X} & =\frac{\partial \Delta}{\partial z_{C}^{*}} \times \frac{\partial z_{C}^{*}}{\partial X}=\left(\frac{a}{2 \times\left[z_{C}^{*}-(\alpha-\beta) \times M\right]^{2}} \times\left[\left(z_{C}^{*}\right)^{2}-2 \times(\alpha-\beta) \times M \times z_{C}^{*}\right]\right) \times\left(\frac{1}{a}\right) \\
& =\frac{1}{2 \times\left[z_{C}^{*}-(\alpha-\beta) \times M\right]^{2}} \times\left[\left(z_{C}^{*}\right)^{2}-2 \times(\alpha-\beta) \times M \times z_{C}^{*}\right]
\end{aligned}
$$

Hence, $\frac{\partial G}{\partial X}=1-\left[\frac{\partial p}{\partial X} \times\left[X+\left(f_{L}-f_{D}\right)+g \times C\right]+p\right]-\left[\frac{\partial(1-p)}{\partial X} \times \Delta+(1-p) \times \frac{\partial \Delta}{\partial X}\right]$

It can be simplified that

$$
\frac{\partial G}{\partial X}=\left(\frac{1}{2 \beta M}\right) \times\left(z_{C}^{*}+(\beta-\alpha) \times M\right)>0 \quad \text { because } \quad \alpha \leq \beta \quad \text { and } \quad 0 \leq z_{C}^{*} \leq R<M .
$$

Case 2: $\quad z_{C}^{*}=R$ 
$p=\left[\frac{(\alpha+\beta) \times M-R}{2 \beta M}\right]$ and $1-p=\left[\frac{R-(\alpha-\beta) \times M}{2 \beta M}\right]$

$G(X, C)$

$=\left[X+\left(f_{L}-f_{D}\right)\right]-\left\{\begin{array}{l}{\left[\frac{(\alpha+\beta) \times M-R}{2 \beta M}\right] \times\left[X+\left(f_{L}-f_{D}\right)+g \times C\right]} \\ +\left[\frac{R-(\alpha-\beta) \times M}{2 \beta M}\right] \times\left[\left(\frac{a}{2 \times[R-(\alpha-\beta) \times M]}\right) \times R^{2}\right]\end{array}\right\}$

$\frac{\partial G}{\partial X}=\left[\frac{(\beta-\alpha) \times M+R}{2 \beta M}\right]>0 \quad$ because $\quad \alpha \leq \beta \quad$ and $\quad 0<R<M$.

Hence, $\frac{\partial G}{\partial X}<0$ for all $X$, given that $\alpha \leq \beta$ and $0<R<M$.

Given the result that $G(X, C)$ is increasing with $X$, it is easy to prove $C_{L}^{\text {Indiff }}<C_{H}^{\text {Indiff }}$.

Consider $X_{L}<X_{H}$. By the definition of $C_{L}^{\text {Indiff }}, G\left(X=X_{L}, C=C_{L}^{\text {Indiff }}\right)=0$. Since $\frac{\partial G}{\partial X}>0$,

$G\left(X=X_{H}, C=C_{L}^{\text {Indidf }}\right)>0$. Furthermore, according to Appendix A.5, $\frac{\partial G}{\partial C}<0$. Hence, if

$G\left(X=X_{H}, C=C_{H}^{\text {Indiff }}\right)=0$, we have $C_{L}^{\text {Indiff }}<C_{H}^{\text {Indiff }}$.

- End of Proof - 


\section{REFERENCES}

Bensaid, B. and O. Jeanne, 1997, "The Instability of Fixed Exchange Rate Systems when Raising the Nominal Interest Rate is Costly," European Economic Review, 41, 1461-1478.

Chan, Alex and Nai-fu Chen, 1999, "An Intertemporal Currency Board," Pacific Economic Review, $4,215-232$

Chen, Nai-fu, 2001, "The Hong Kong Currency Board during 1997-98 Crisis: Problems and Solutions," International Review of Finance, 2, 99-112

Culp, C. L., Hanke, S. H. and M. Miller, 1999, "The Case for an Indonesian Currency Board," Journal of Applied Corporate Finance, 11, num 4, 57-65.

De Grauwe, Paul, 1997, “the Economics of Monetary Integration,” Oxford University Press.

Diamond, D. W. and P. H. Dybvig, 1983, "Bank Runs, Deposit Insurance, and Liquidity," Journal of Political Economy, 91, 401-419.

Jeanne, O., 1997, “Are Currency Crises Self-Fulfilling? A Test,” Journal of International Economics, 43, 263-286.

Hanke, S. H., L. Jonung and K. Schuler, 1993. Russian Currency and Finance. London: Routledge.

Hanke, S. H., 2002, "Currency Boards," Annals of the American Academy of Political and Social Science, $87-105$.

Krugman, P., 1979, “A Model of Balance-of-Payments Crises," Journal of Money, Credit and Banking, 11, 311-325.

_— 1996, “Are Currency Crises Self-Fulfilling?,” NBER Macroeconomics Annual, 345-378

Miller, M., 1998a, "The Current Southeast Asia Financial Crisis," Pacific-Basin Finance Journal, 6, 225-233. 
— 1998b, “Some Reflection on Recent Monetary Turmoil in Eastern Europe," Journal of Applied Corporate Finance, 11, num 3, 49-54.

-2000, "Exchange rate policy options for Southeast Asia," International Review of Finance, 1, 3-10.

Morgan Stanley Dean Witter, November 1998, Understanding the Hong Kong Currency Board.

Mundell, R. A., 1961, “A Theory of Optimal Currency Areas,” American Economic Review 51, 657-65.

Mundell, R. A., 2000, “A Reconsideration of the Twentieth Century,” American Economic Review, 90, 327-340.

Obstfeld, M., 1986, "Rational and Self-Fulfilling Balance of Payments Crises," American Economic Review, 76, 72-81.

— 1996, "Models of Currency Crises with Self-Fulfilling Features," European Economic Review, 40, 1037-1047.

Svensson, L., 1994, "Fixed Exchange Rates as a Means to Price Stability: What Have We Learned?," European Economic Review, 38, 447-468. 


\section{Figure 1}

\section{Exogenous Money Demand Contraction Shock and Government's Decision}

\begin{tabular}{|c|c|c|}
\hline & & $\begin{array}{r}\text { Exogenous m } \\
\text { demand contra } \\
\text { shock }(S)\end{array}$ \\
\hline & 1 & 1 \\
\hline & $(+R)$ & $(+M)$ \\
\hline $\begin{array}{l}\text { For }(S<0) \text {, an expansion in the } \\
\text { demand for domestic currency } \\
\text { induces an inflow of foreign } \\
\text { currency to the currency board. } \\
\text { The government will maintain } \\
\text { the currency board. }\end{array}$ & $\begin{array}{l}\text { A contraction in domestic money } \\
\text { demand induces an outflow of foreign } \\
\text { reserve from the currency board. As } \\
\text { the outflow is less the foreign reserve } \\
\text { holding, the government may maintain } \\
\text { or voluntarily abandon the currency } \\
\text { board in accordance with its social loss } \\
\text { function. }\end{array}$ & $\begin{array}{l}\text { A large contraction in domestic } \\
\text { money demand induces a large } \\
\text { demand for conversion of foreign } \\
\text { currency at the official exchange } \\
\text { rate. Due to insufficient foreign } \\
\text { reserve, the government is forced } \\
\text { to abandon the currency board. }\end{array}$ \\
\hline
\end{tabular}




\section{Figure 2}

\section{Time Line for the One-Period Model}

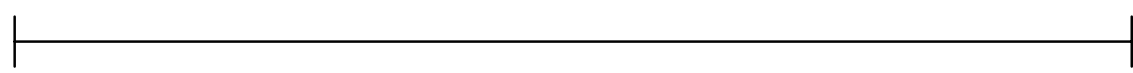

Given the foreign reserve level $(R)$, fundamental values $\left(F_{D}, F_{L}\right)$, the government's determination $(X)$ and other parameters,

the public will panic run (sell $Q^{*}$ of domestic currency) if the implied delink probability $p$ is higher than the threshold $p^{*}$.

If there is a panic run against the currency board, the government has no choice but to abandon the currency board involuntarily.
If there is no panic run at $t=0$, the decision for the abandonment of currency board will be made at time $t=1$.

Realization of an exogenous money demand contraction shock $(S)$, which is publicly observable.

If the money demand contraction shock is larger than the foreign reserve holding, the government will abandon the currency board involuntarily.

Otherwise, the government can decide whether to maintain or voluntarily abandon the currency board in accordance with its social loss function. 
\begin{tabular}{|l}
\hline Figures 3a \\
\hline
\end{tabular}

Maximum Tolerance for External Shock $\left(z^{*}\right)$ at $\mathbf{t}=1$

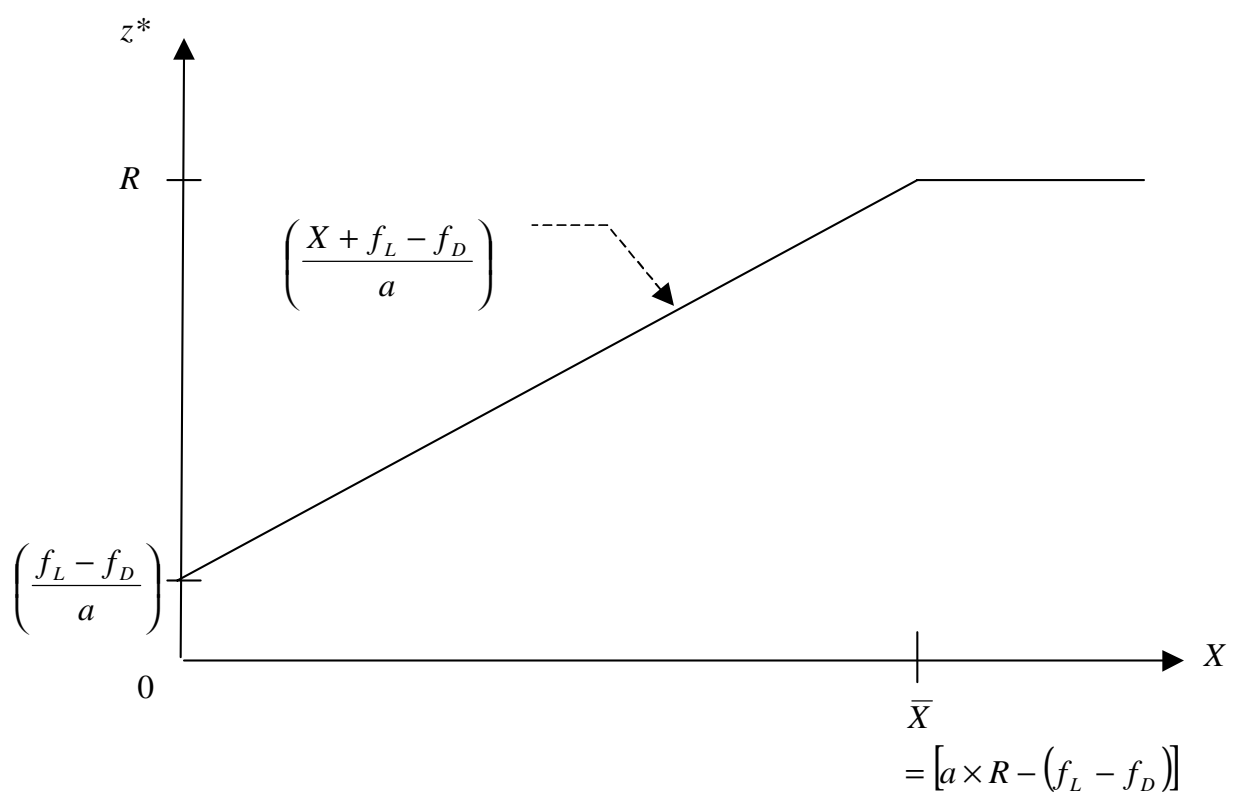




\section{Figure 3b}

\section{Implied Delink Probability $(p)$ at $\mathrm{t}=1$}

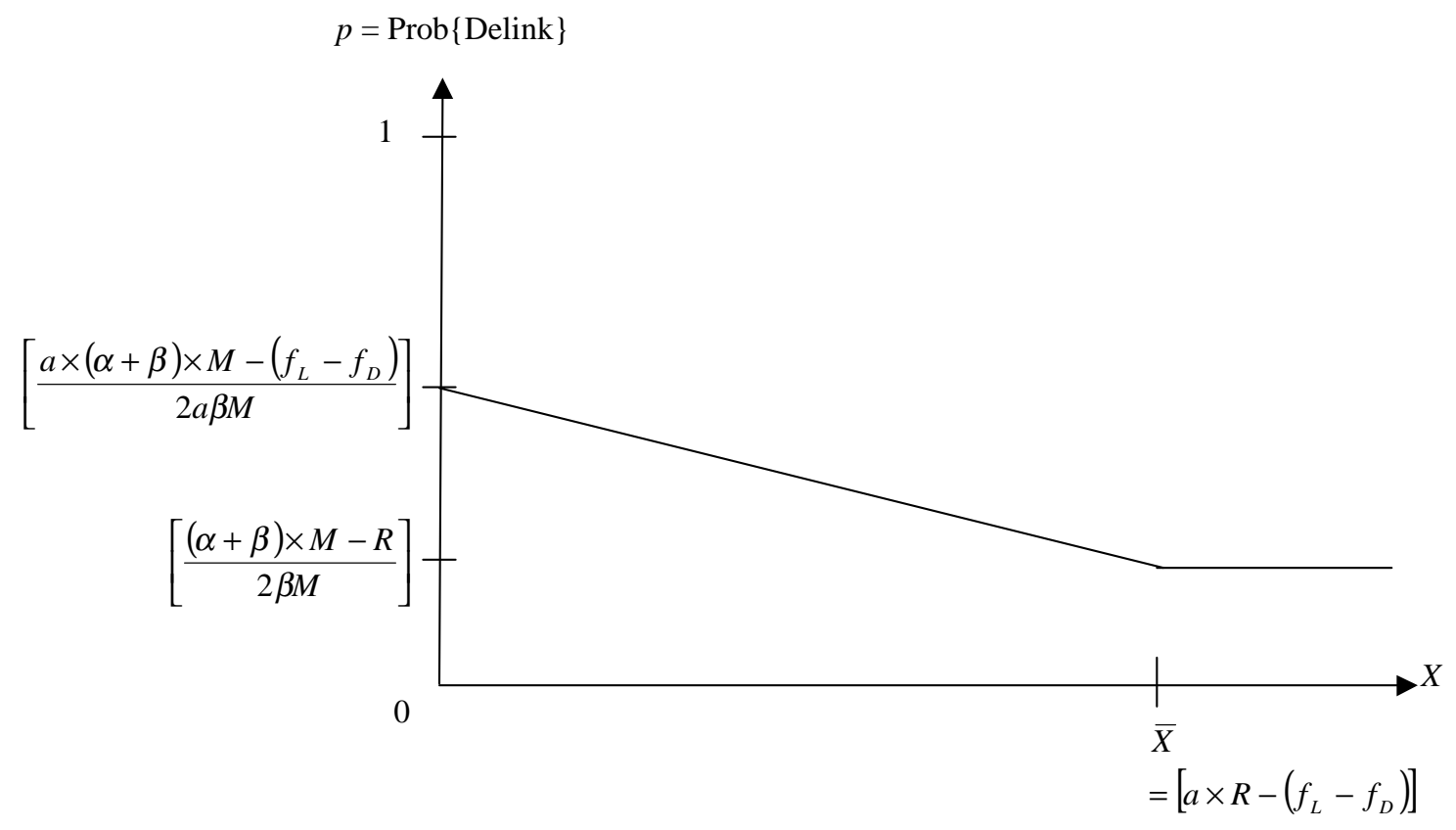




\section{Figure 4}

Threshold Probability ( $p^{*}$, the Public's Risk Tolerance) and the Implied Delink Probability at $\mathrm{t}=1$

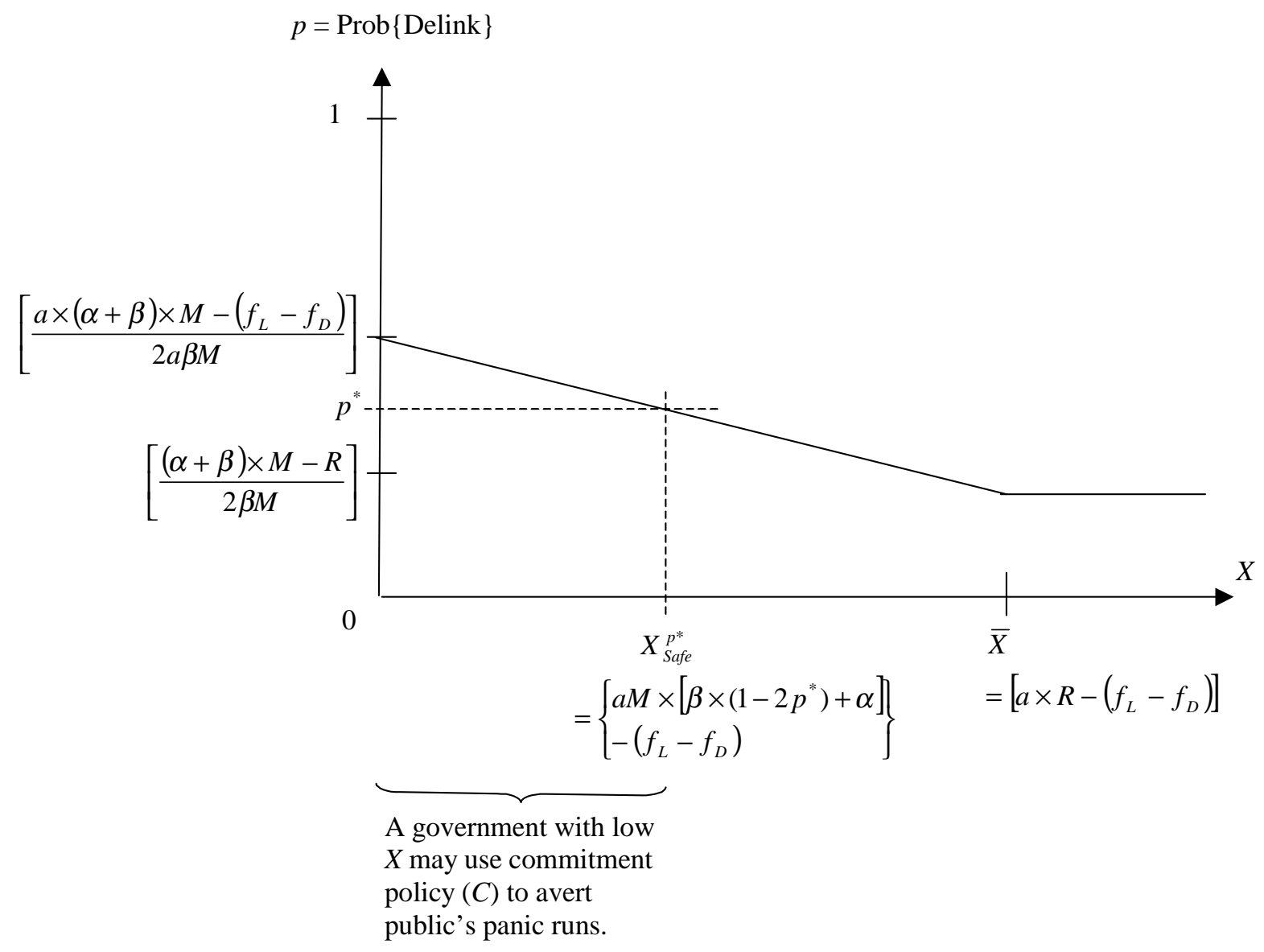




\section{Figure 5}

Government's Delink Decision Conditional on a Foreign Reserve Commitment Policy $(C)$ and the Realization of an Exogenous Money Demand Contraction Shock at $\mathrm{t}=1$

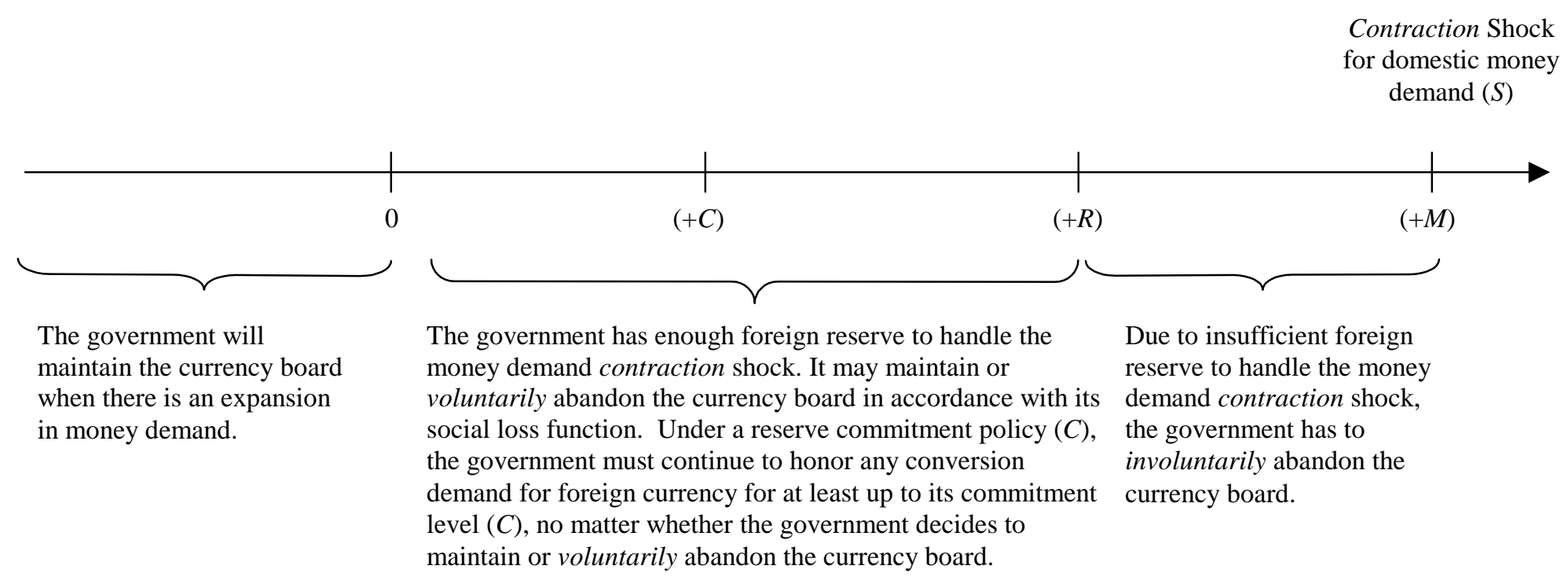




\section{Figures 6a}

Maximum Tolerance for External Shock $\left(z_{C}^{*}\right)$ at $\mathbf{t}=1$ Conditional on Commitment Policy $(C)$

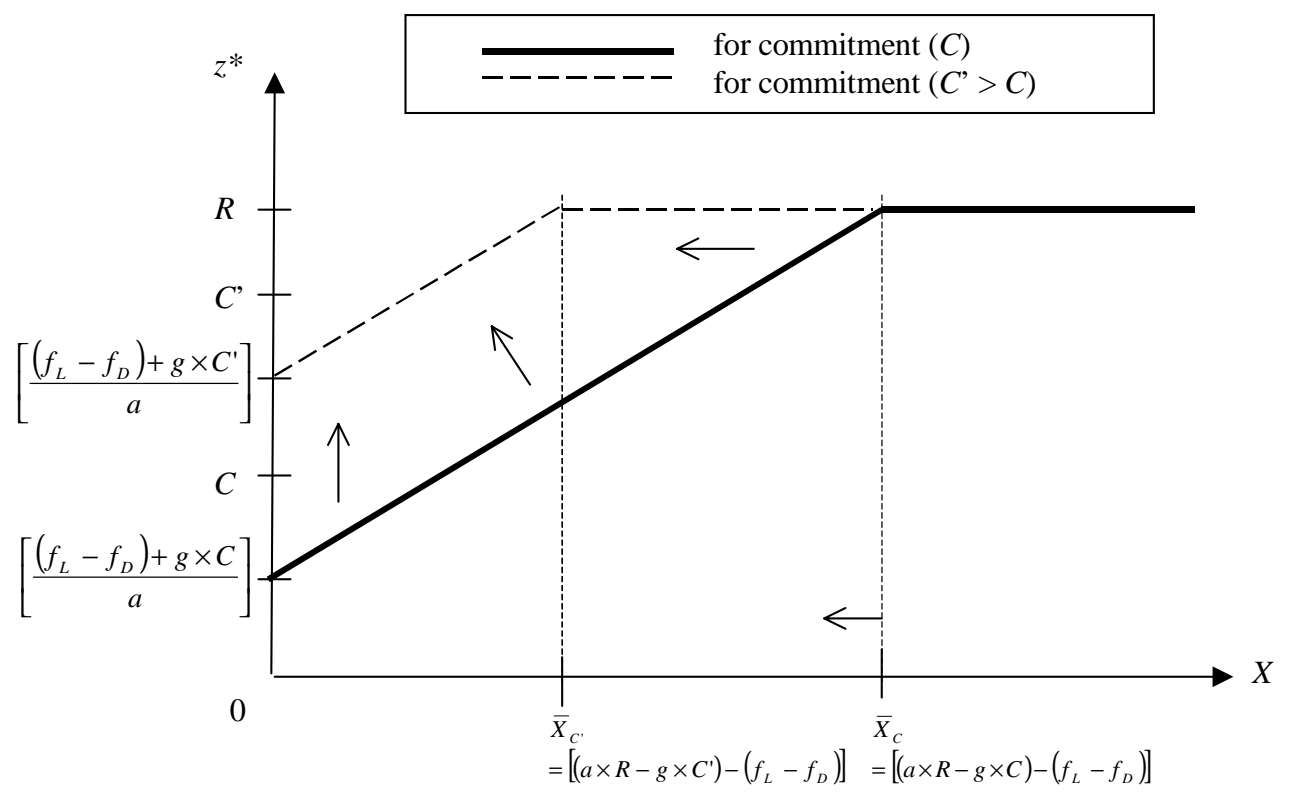




\section{Figure 6b}

Implied Delink Probability $\left(p_{C}\right)$ at $\mathbf{t}=1$ Conditional on Commitment Policy $(C)$

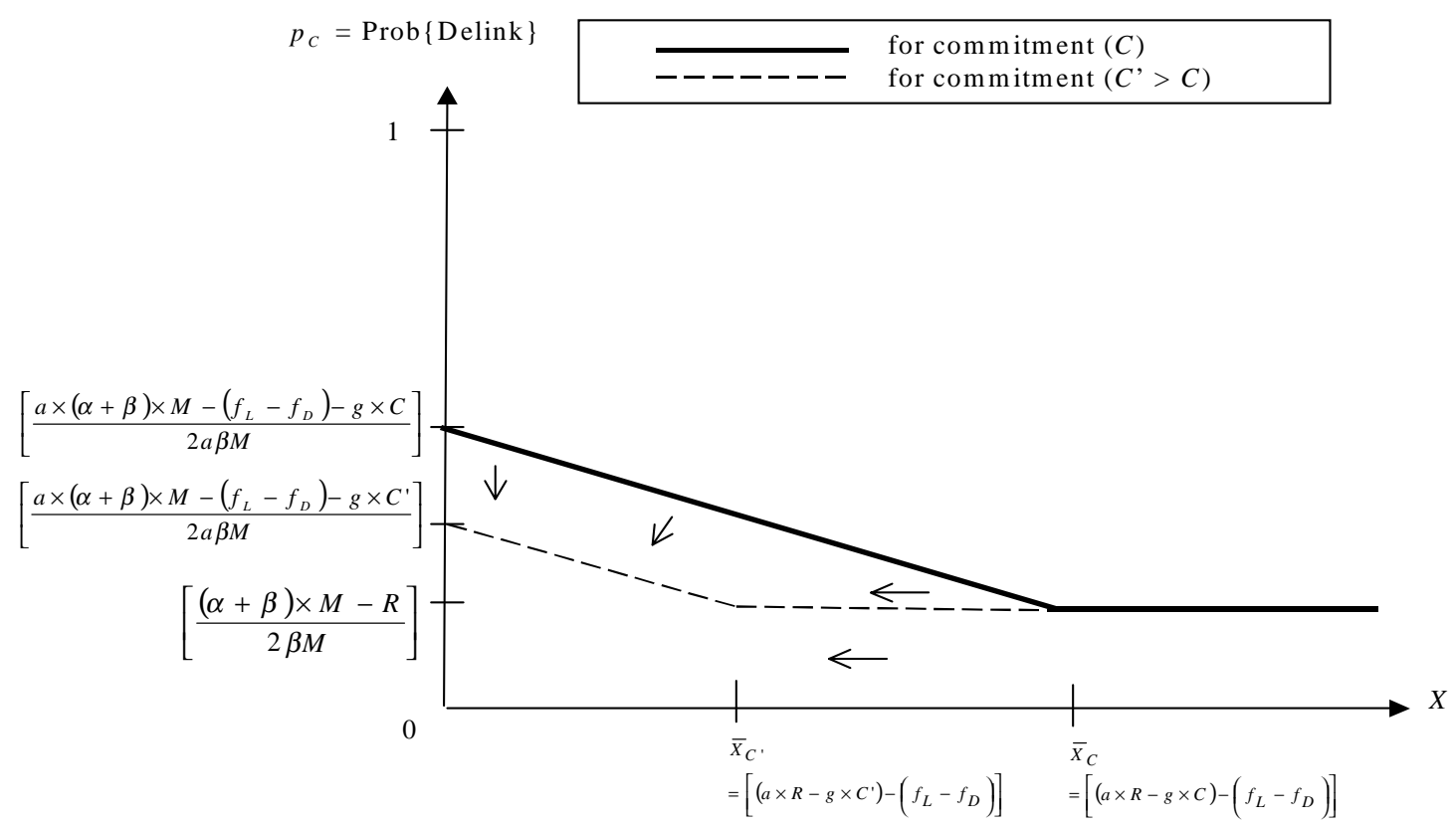




\section{Figure 7}

The Optimal Commitment Level $C^{p^{*}}(X)$ at $\mathrm{t}=0$ to Avert Public's Panic Selling Given a value of $\left(p^{*}\right)$,

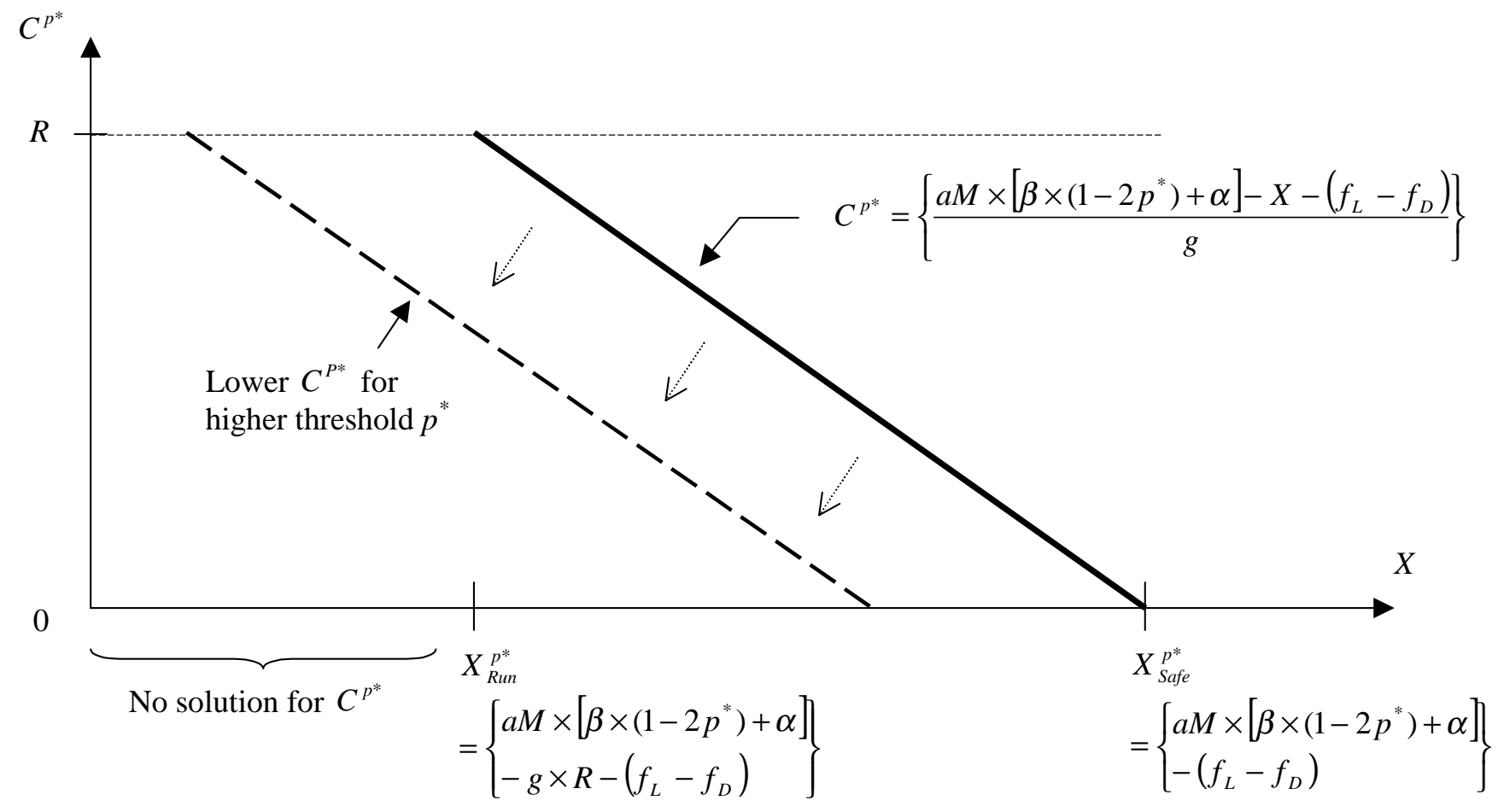




\section{Figure 8}

\section{Gain from Using $C^{p^{*}}(X)$ to Avert Public's Panic Selling}

With perfect information on $X$, the gain of a government with determination $X$ (value on the $\mathrm{X}$-axis) from using reserve commitment $C^{p^{*}}(X)$ to avert a public's panic run is $G\left(X, p^{*}\right)$, which is the difference between the expected social loss with a panic run, $E[L \mid C=0$, with Panic Run], and the expected social loss under reserve commitment policy $C^{p^{*}}(X)$ and no panic run, $E\left[L \mid C=C^{p^{*}}(X)\right.$, without Panic Run $]$. The $X_{\text {Indiff }}^{p^{*}}$, the $X$-intercept for $G\left(X, p^{*}\right)$, is the critical value of determination such that a government with $X_{\text {Indiff }}^{p^{*}}$ is indifferent to abandoning the currency board versus averting panic run by committing $C^{p^{*}}(X)$.

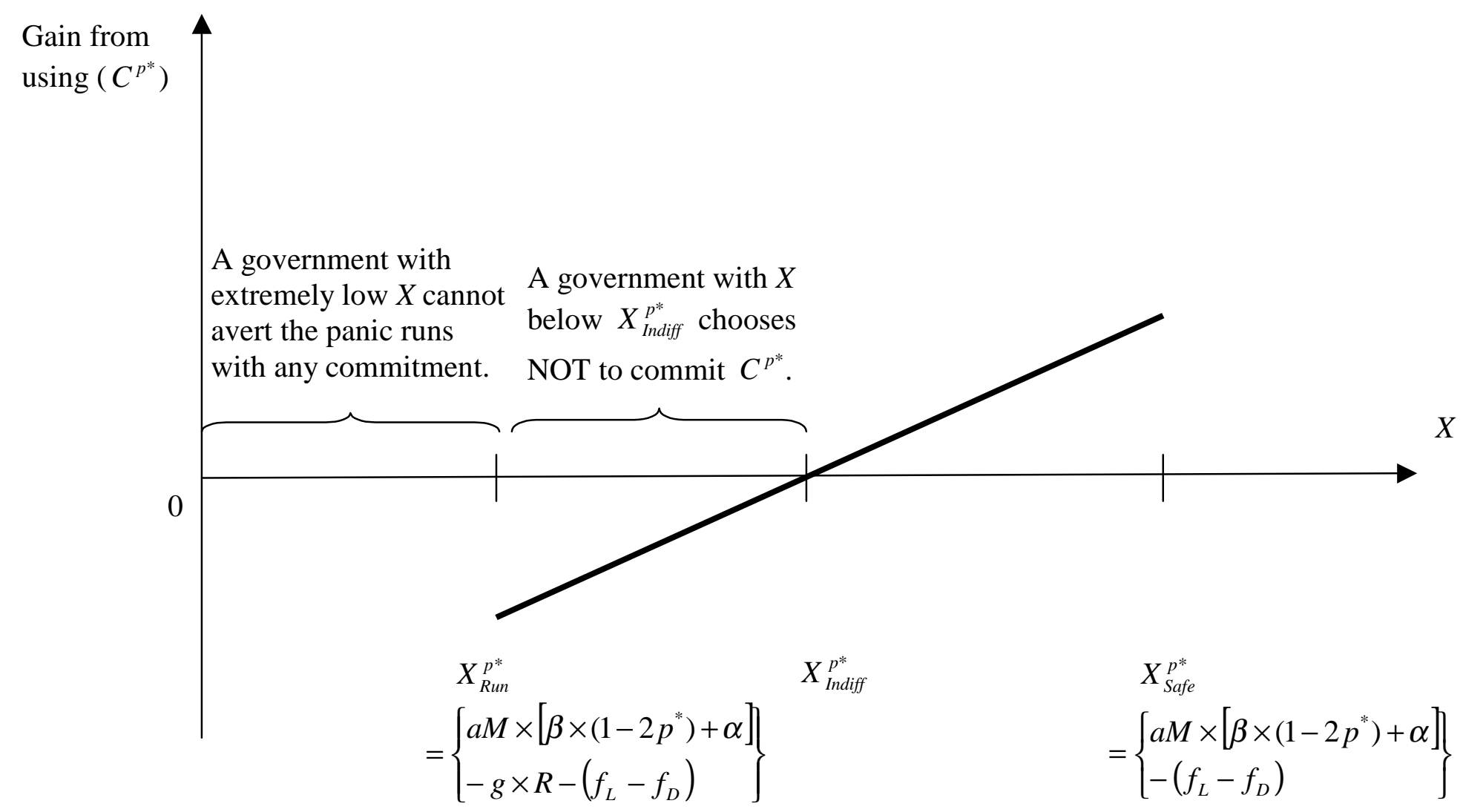




\section{Figure 9}

\section{Gain to a Government with $X_{L}$ from Imitation if a Government with $X_{H}$ Commits $C_{H}^{p^{*}}$}

With asymmetric information on the government's determination $X$, the imitation gain of a government with a low determination $X_{L}$ (value on the $\mathrm{X}$-axis) from using reserve commitment $C_{H}^{p^{*}}$ to imitate a government with high determination $X_{H}$, is $G I\left(X_{L}, X_{H}\right)$, which is the difference between the expected social loss to $X_{L}$ with a panic run, $E\left[L \mid X=X_{L}, C=0\right.$, with Panic Run], and the expected social loss under reserve commitment policy $C_{H}^{p^{*}}$ and no panic run, $E\left[L \mid X=X_{L}, C=C_{H}^{p^{*}}\right.$, without Panic Run $]$. The $X^{\#}$, the $X$-intercept for $G I\left(X_{L}, X_{H}\right)$, is the critical value of determination such that a government with $X^{\#}$ is indifferent to imitating the $X_{H}$ with committing $C_{H}^{p^{*}}$ versus not committing.

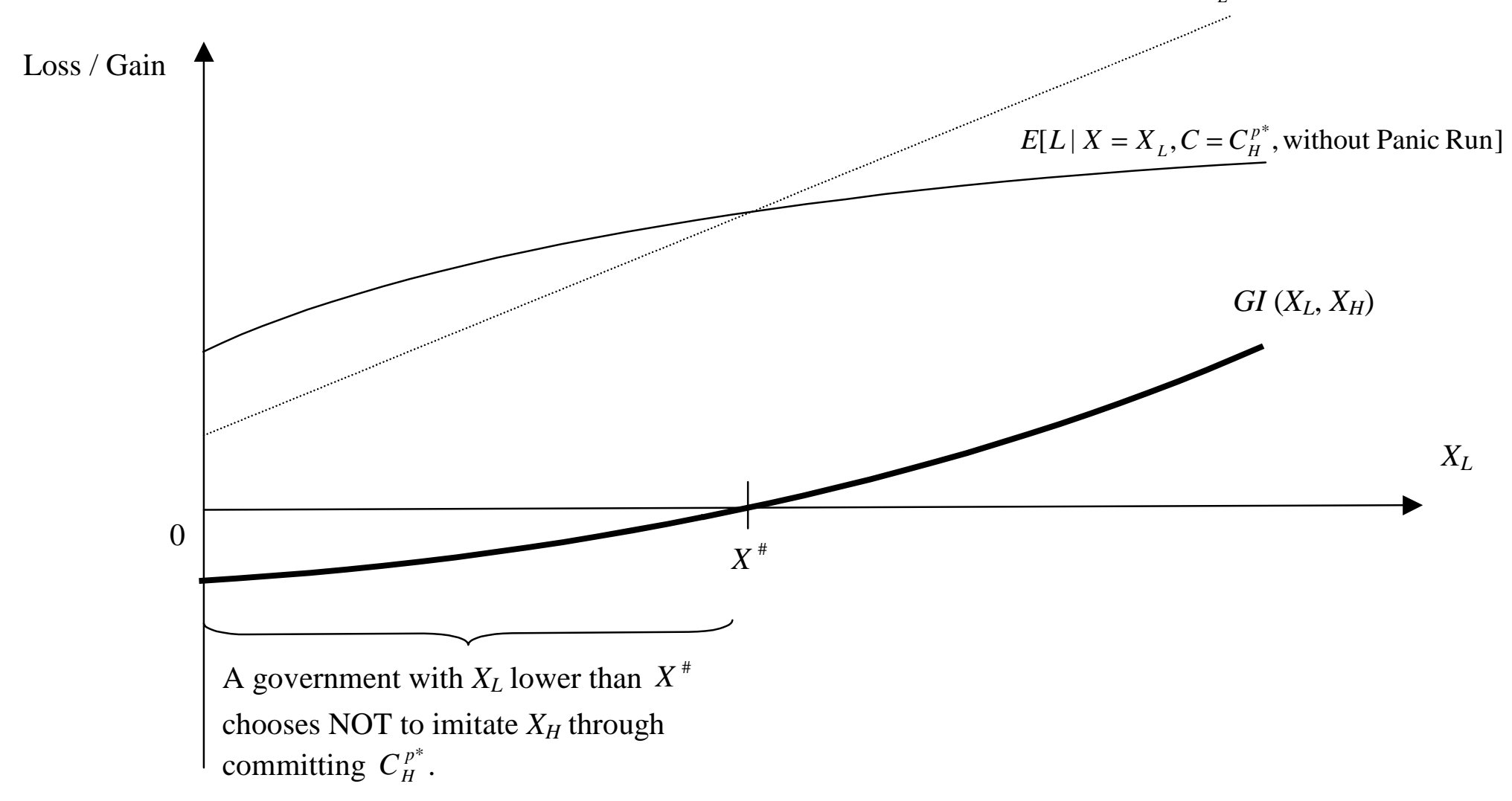




\section{Figure 10a}

\section{Hong Kong's Simulation (a): Optimal Reserve Commitment for Large $X_{H}\left(X_{H}=3>X_{\text {Safe }}^{p^{*}}\right)$}

Given parameters $a=0.5,\left(f_{L}-f_{D}\right)=1, g=0.35, p^{*}=0.1, M=20, \alpha=0.05, \beta=0.4, R=8$, and $X_{H}=3\left(X_{H}>X_{S a f e}^{p^{*}}\right)$, with perfect information, a government with $X_{H}$ will not face any panic run. With asymmetric information on the government's determination $X$, if the public underestimates its determination to be $X_{L}$ (value on the $X$ axis), the government may have to commit some reserves to avert panic runs in accordance with the public's estimate $X_{L}$. Case (i): if $X_{L}<X_{\text {Sep }}^{p^{*}}$, the government will commit $C_{L}^{\text {Indiff }}$, which is the reserve commitment such that $X_{L}$ is indifferent to imitating $X_{H}$ (separating equilibrium). Case (ii): if $X_{\text {Sep }}^{p^{*}} \leq X_{L}<X_{\text {Safe }}^{p^{*}}$, the government will commit $C_{L}^{p^{*}}$ (good pooling equilibrium). Case (iii): if $X_{\text {Safe }}^{p^{*}} \leq X_{L}$, the government does not need to commit any reserve (good pooling equilibrium).

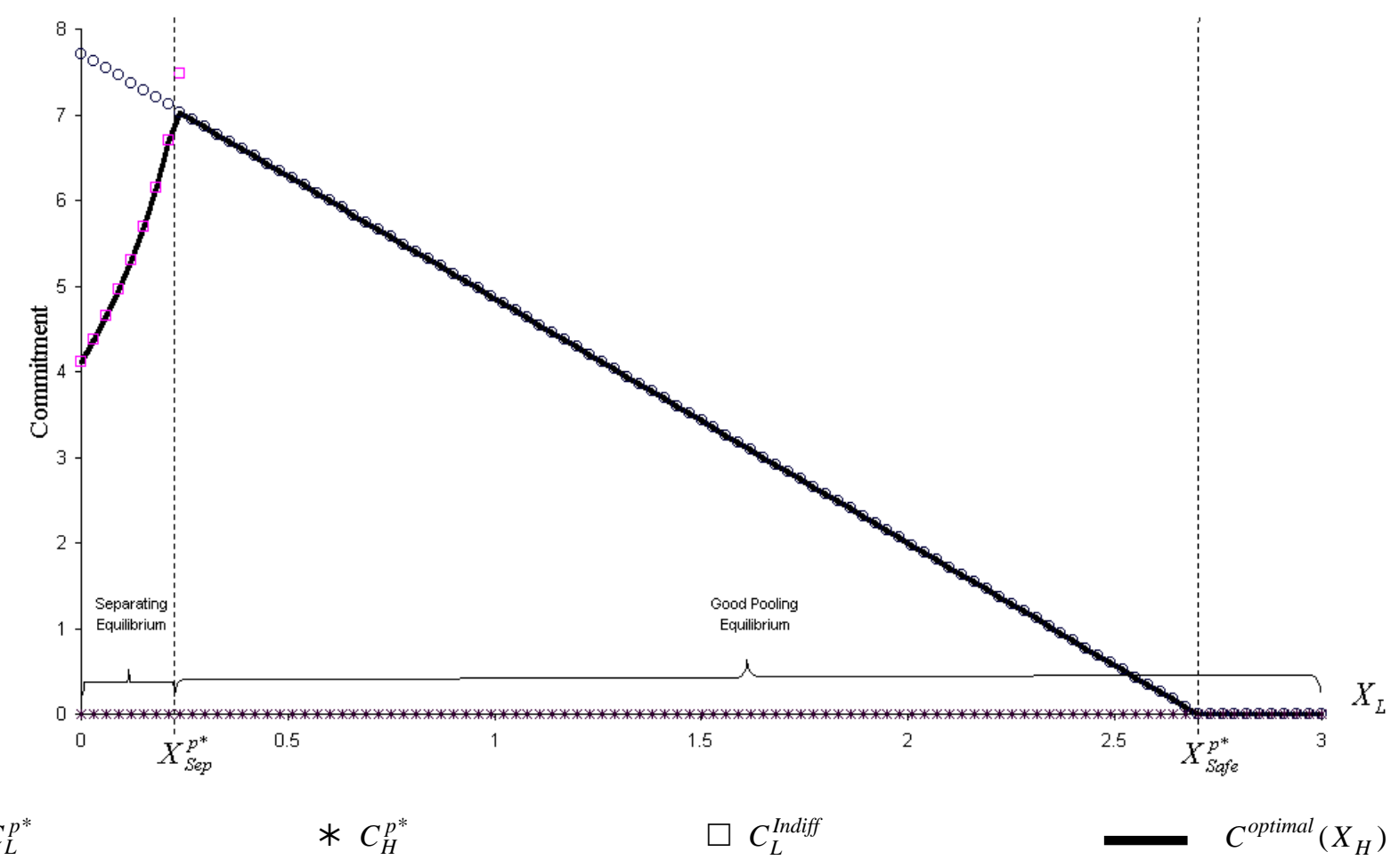




\section{Figure 10b}

\section{Hong Kong's Simulation (b): Optimal Reserve Commitment for Small $X_{H}\left(X_{H}=1<X_{\text {Safe }}^{p^{*}}\right)$}

Given parameters $a=0.5,\left(f_{L}-f_{D}\right)=1, g=0.35, p^{*}=0.1, M=20, \alpha=0.05, \beta=0.4, R=8$, and $X_{H}=1\left(X_{H}<X_{\text {Safe }}^{p^{*}}\right.$ ), even with perfect information, a government with $X_{H}$ has to commit $C_{H}^{p^{*}}=4.9$ to avert panic runs. With asymmetric information on the government's determination $X$, if the public underestimates its determination to be $X_{L}$ (value on the X-axis), the government may have to commit extra reserves to avert panic runs in accordance with the public's estimate $X_{L}$. Case (i): if $X_{L}<X_{S e p}^{p^{*}}$, the government will commit $\max \left\{C_{H}^{p^{*}}, C_{L}^{\text {Indiff }}\right\}$ to avert panic runs (separating equilibrium). Case (ii): if $X_{\text {Sep }}^{p^{*}} \leq X_{L}<X_{H}$, the government will commit $C_{L}^{p^{*}}$ (good pooling equilibrium).

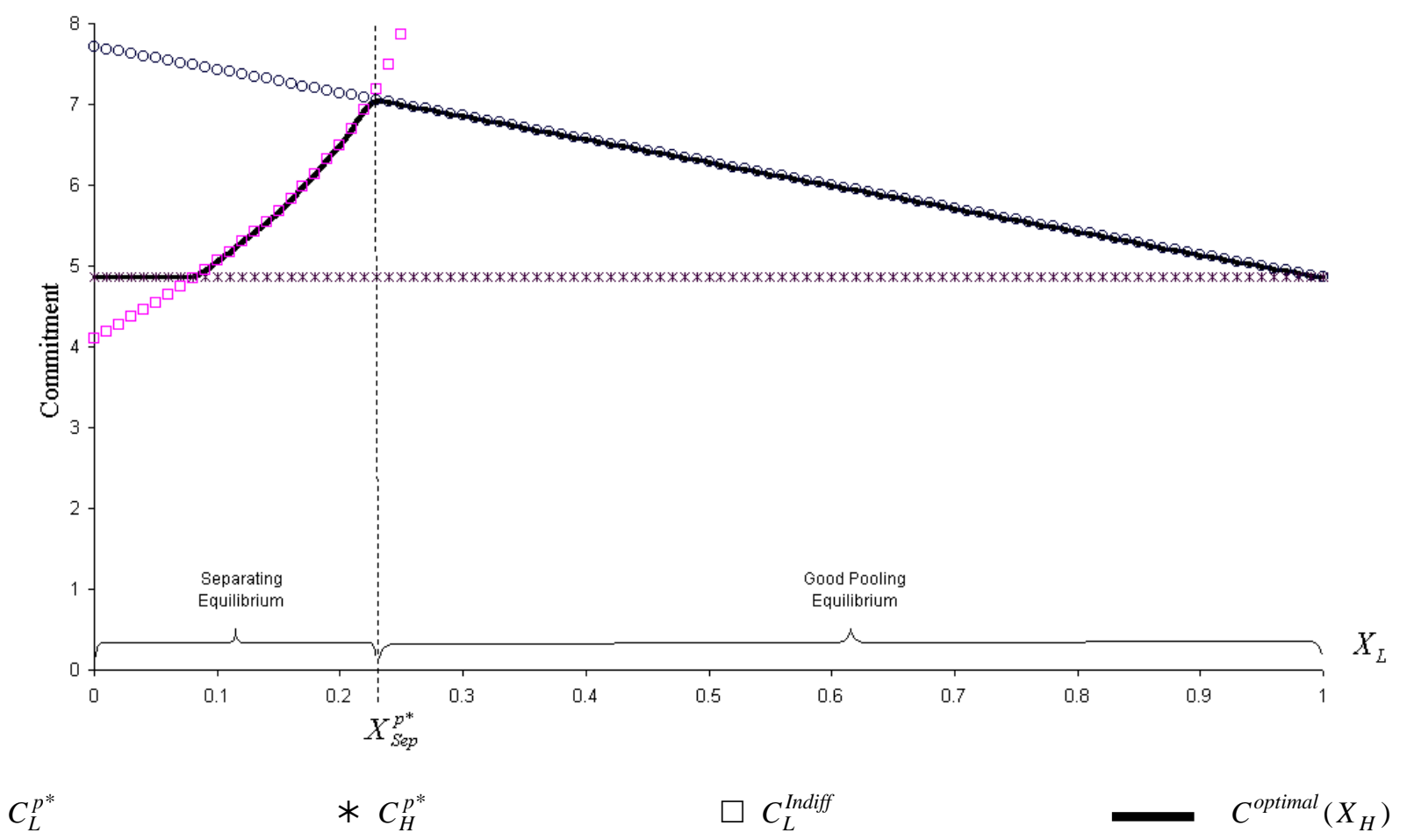




\section{Figure 10c}

\section{Hong Kong's Simulation (c): Optimal Reserve Commitment for Small $\mathbf{g}$}

Given parameters $a=0.5,\left(f_{L}-f_{D}\right)=1, g=0.25, p^{*}=0.1, M=20, \alpha=0.05, \beta=0.4, R=8$, and $X_{H}=3\left(X_{H}>X_{\text {Safe }}^{p^{*}}\right)$, with perfect information, a government with $X_{H}$ will not face any panic run. With asymmetric information on the government's determination $X$, if the public underestimates its determination to be $X_{L}$ (value on the $\mathrm{X}$ axis), the government may have to commit some reserves to avert panic runs in accordance with the public's estimate $X_{L}$. Case (i): if $X_{L}<X_{\text {Sep }}^{p^{*}}$, the government will commit $C_{L}^{\text {Indiff }}$ (separating equilibrium). Case (ii): if $X_{R u n}^{p^{*}} \leq X_{L}<X_{\text {Safe }}^{p^{*}}$, the government will commit $C_{L}^{p^{*}}$ (good pooling equilibrium). Case (iii): if $X_{\text {Safe }}^{p^{*}} \leq X_{L}$, the government does not need to commit any reserve (good pooling equilibrium). Case (iv): if $X_{\text {Sep }}^{p^{*}} \leq X_{L}<X_{\text {Run }}^{p^{*}}$, due to limited reserves the government cannot commit enough to separate itself from $X_{L}$ to avert panic runs (bad pooling equilibrium).

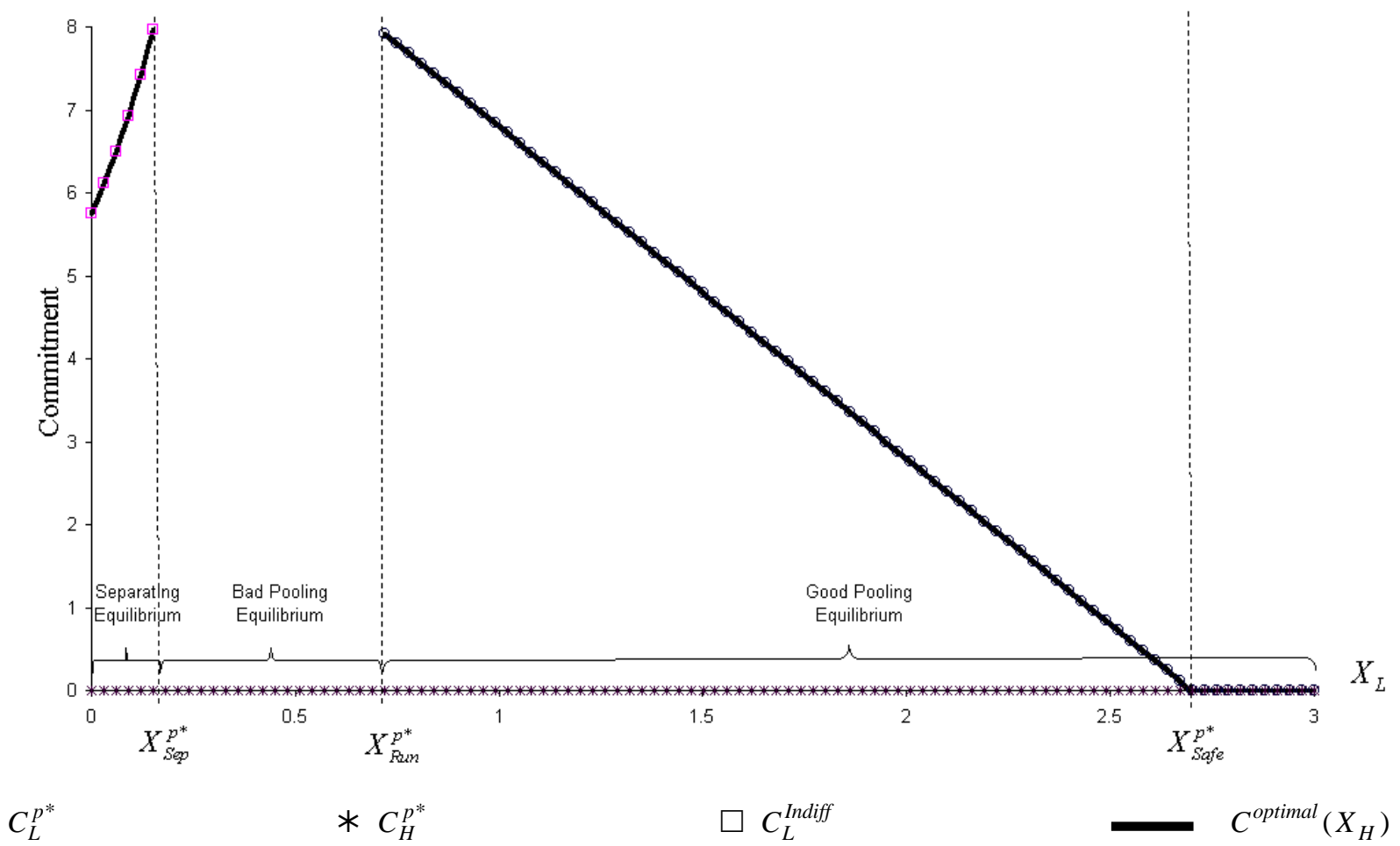




\section{Figure 11a}

\section{Argentina's Simulation (a): No Feasible Reserve Commitment to Avert Panic Runs}

Given parameters $a=1,\left(f_{L}-f_{D}\right)=1, g=0.35, p^{*}=0.1, M=20, \alpha=0.1, \beta=0.4, R=10$, and $X_{H}=3$ ( $X_{H}<X_{\text {Safe }}^{p^{*}}$ ), even with perfect information, a panic run is unavoidable because a government with $X_{H}$ has to commit $C_{H}^{p^{*}}=12.6$ to avert the panic run but the available reserve is only 10 . Hence, $C_{H}^{p^{*}}$ is infeasible.

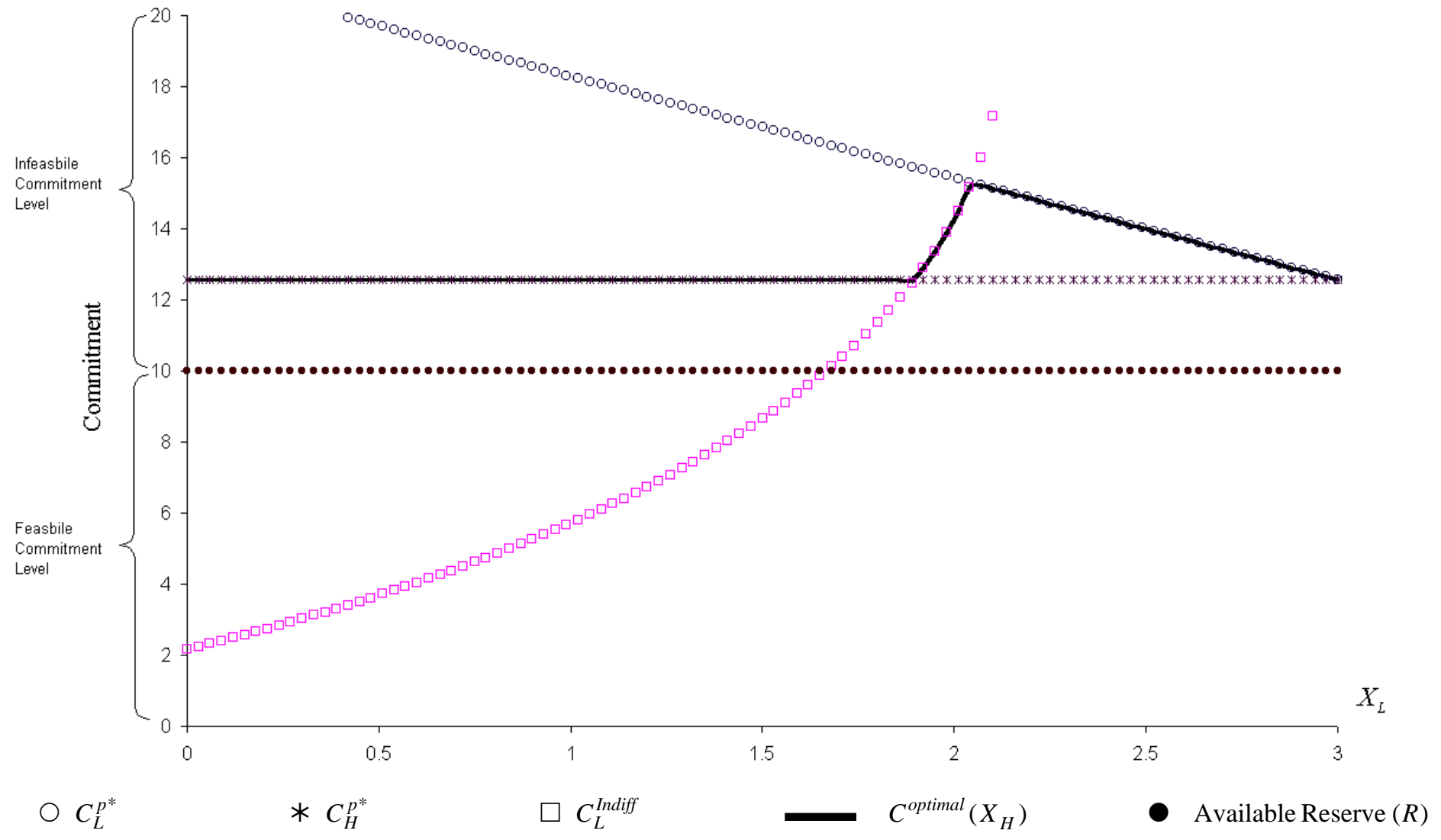




\section{Figure 11b}

\section{Argentina's Simulation (b): Existence of Feasible Reserve Commitment to Avert Panic Runs for Larger $\boldsymbol{X}_{H}$}

Given parameters $a=1,\left(f_{L}-f_{D}\right)=1, g=0.35, p^{*}=0.1, M=20, \alpha=0.1, \beta=0.4, R=10$, and $X_{H}=4$ ( $X_{H}<X_{\text {Safe }}^{p^{*}}$ ), with perfect information, a government with $X_{H}$ has to commit $C_{H}^{p^{*}}=9.7$ to avert panic runs. Under asymmetric information on the government's determination $X$, if the public underestimates its determination to be $X_{L}$ (value on the $\mathrm{X}$-axis), the government may have to commit more reserves to avert panic runs in accordance with the public's estimate, $X_{L}$. Case (i): if $X_{L}<X_{\text {Sep }}^{p^{*}}$, the government will commit $\max \left\{C_{H}^{p^{*}}, C_{L}^{\text {Indiff }}\right\}$ (separating equilibrium). Case (ii): if $X_{R u n}^{p^{*}} \leq X_{L}<X_{H}$, the government will commit $C_{L}^{p^{*}}$ (good pooling equilibrium). Case (iii): if $X_{S e p}^{p^{*}} \leq X_{L}<X_{R u n}^{p^{*}}$, due to limited reserves the government cannot commit enough to separate itself from $X_{L}$ to avert panic runs (bad pooling equilibrium).

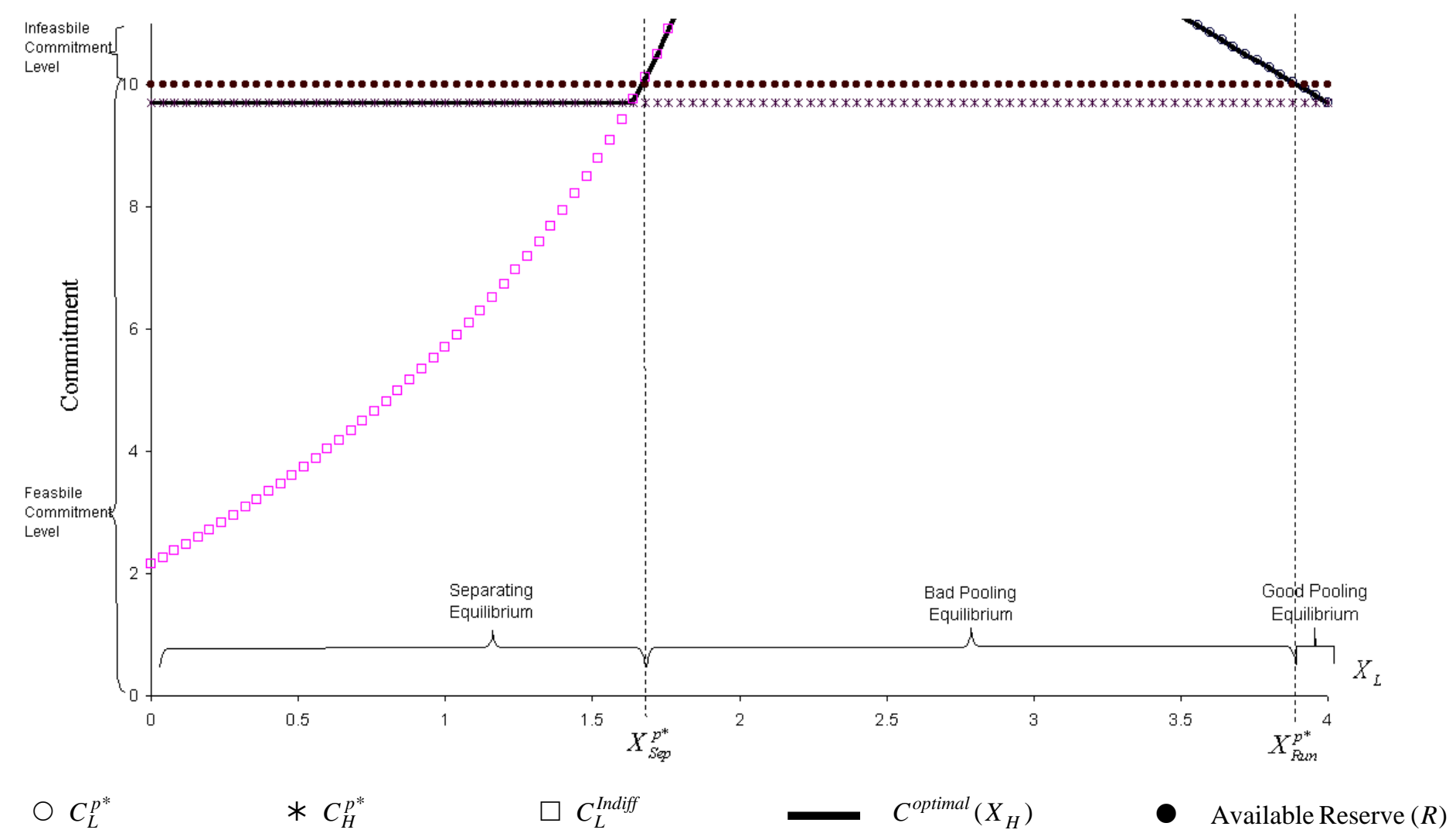




\section{Figure 11c}

\section{Argentina's Simulation (c): Existence of Feasible Reserve Commitment to Avert Panic Runs for Large $X_{H}$ and Small $a$}

Given parameters $a=0.5,\left(f_{L}-f_{D}\right)=1, g=0.35, p^{*}=0.1, M=20, \alpha=0.1, \beta=0.4, R=10$, and $X_{H}=3\left(X_{H}<X_{\text {Safe }}^{p^{*}}\right.$ ), with perfect information, a government with $X_{H}$ has to commit $C_{H}^{p^{*}}=0.57$ to avert panic runs. With asymmetric information on the government's determination $X$, if the public underestimates its determination to be $X_{L}$ (value on the X-axis), the government may have to commit extra reserves to avert a public panic run in accordance with the public's estimate, $X_{L}$. Case (i): if $X_{L}<X_{\text {Sep }}^{p^{*}}$, the government will commit $\max \left\{C_{H}^{p^{*}}, C_{L}^{\text {Indiff }}\right\}$ (separating equilibrium). Case (ii): if $X_{\text {Sep }}^{p^{*}} \leq X_{L}<X_{H}$, the government will commit $C_{L}^{p^{*}}$ (good pooling equilibrium).

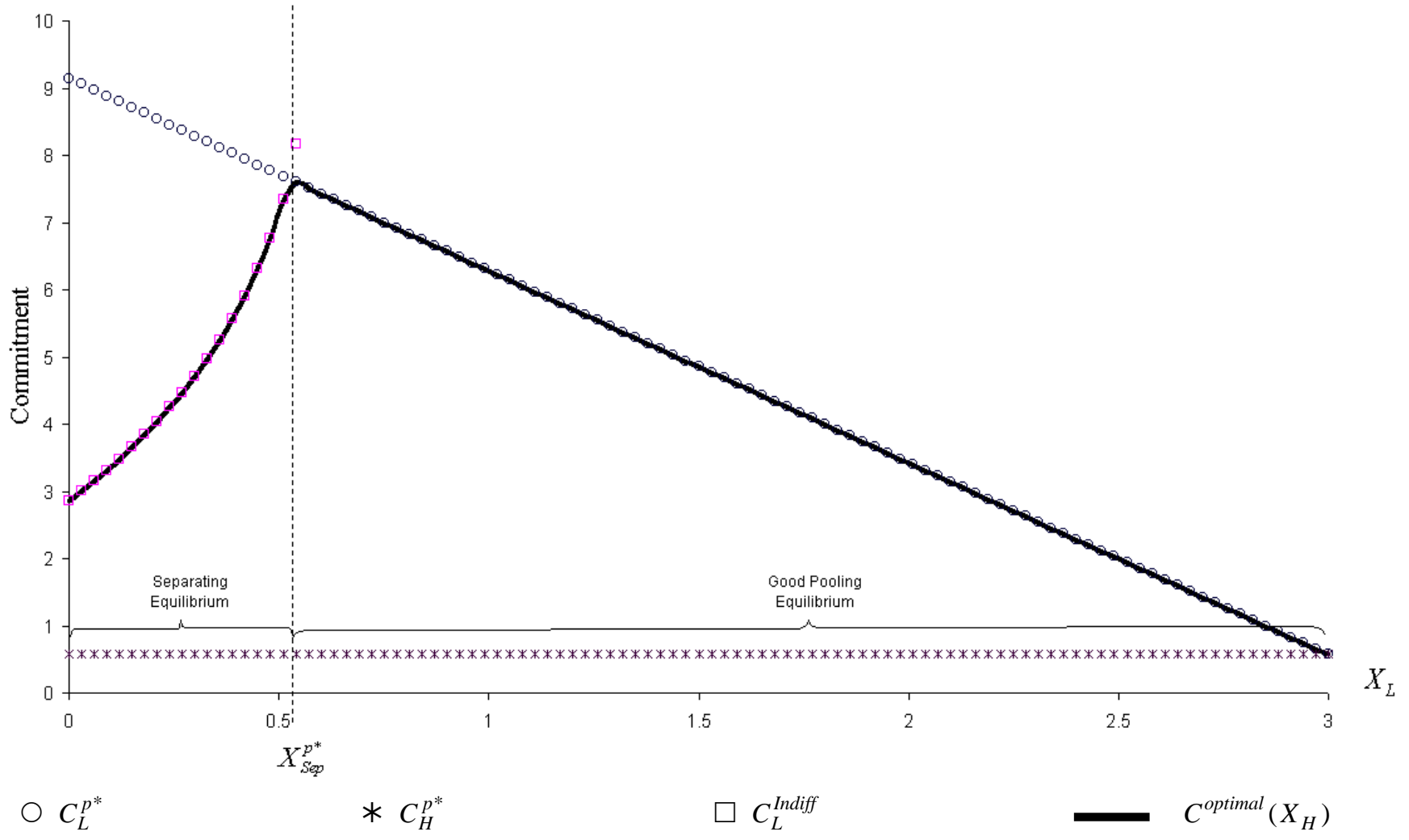

